\title{
The Role of Neural Tissue Engineering in the Repair of Nerve Lesions
}

\section{Arash Abdolmaleki ${ }^{1,2^{*}}$, Asdollah Asadi ${ }^{3}$ Leila Taghizadeh Momen ${ }^{3}$, Shadi Parsi Pilerood ${ }^{3}$}

${ }^{1}$ Department of Engineering Sciences, Faculty of Advanced Technologies, University of Mohaghegh Ardabili, Namin, Iran ${ }^{2}$ Bio Sciences and Biotechnology Research Center (BBRC), Sabalan University of Advanced Technologies (SUAT), Namin, Iran

${ }^{3}$ Department of Biology, Faculty of Sciences, University of Mohaghegh Ardabili, Ardabil, Iran

\section{ABSTRACT}

Introduction: Tissue engineering is the science of tissue design for the healing and regeneration of tissue lesions. Peripheral nerves are typically in danger of physical injury. Peripheral nerve injuries can cause by construction and transport accidents, natural disasters, war-related injuries, and surgical complications. Spontaneous repair of the peripheral nerve is often incomplete, with poor functional recovery. Therefore, nerve tissue engineering researchers have invented scaffolds that can help neural tissue repair due to the type of conformation and their constituents. If the nerve gap in the peripheral nervous system is less than $1 \mathrm{~cm}$ in length, the two ends of the gap can be surgically connected, for larger gaps neural autograft is the gold standard. Applying autograft is restricted due to the deficiency of donor nerves and the requirement of multiple surgeries. The central nervous system is more challenging as the neural repair inhibitor environment is created after injury. Therefore, design of various scaffolds to facilitate nerve tissue repair and regeneration could be a promising method to overcome these problems. Conclusion: Nervous system tissue engineering using nerve scaffolds is one of the therapeutic approaches to replace damaged nerve tissue. To this end, this paper examines the properties of ideal scaffolds and the biomaterials used in scaffold construction, as well as the cells and growth factors appropriate for the treatment of nerve lesions.

\section{Key words:}

1. Tissue Engineering

2. Peripheral Nerves

3. Central Nervous Sys tem

4. Regenerative Medicine

*Corresponding Author: Arash Abdolmaleki

E-mail: Abdolmalekiarash1364@gmail.com 


\title{
نقش مهندسى بافت عصبى درترميهم ضايعات عصبى
}

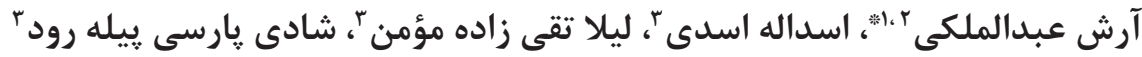 \\ اكروه علوم مهندسى، دانشكده فناورىهاى نوين، دانشخاه محقق اردبيلى، نمين، ايران \\ 'مركز يزوهشى علوم زيستى و زيست فناورى، دانشخاه فناورىهاى نوين سبلان، نمين، ايران \\ "مروه زيستشناسى، دانشكده علوم، دانشعاه محقق اردبيلى، اردبيل، ايران
}

\section{اطلاعات مقاله:}

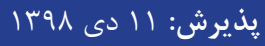

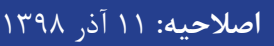

دريافت: ^ץ شهريور

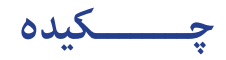

مقدمه: مهندسى بافت علم طراحى بافت براى بهببود و ترميم ضايعات بافتى است. اعصاب محيطى

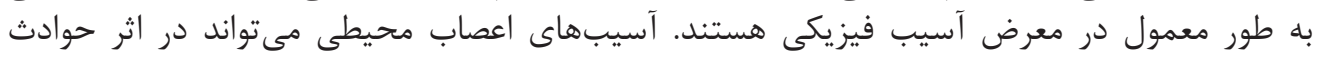

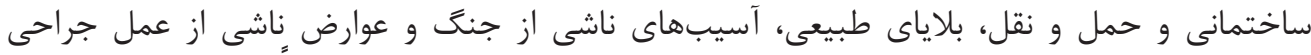

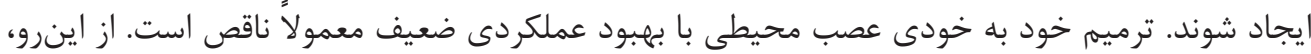

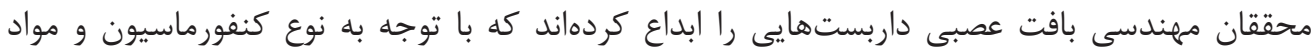

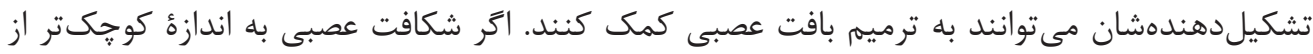

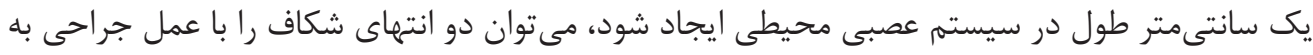

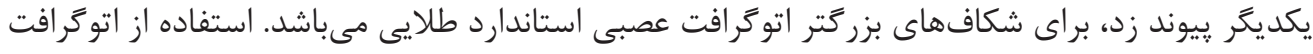

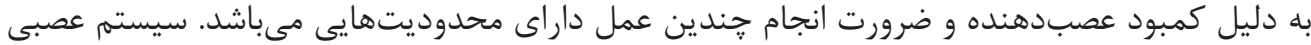

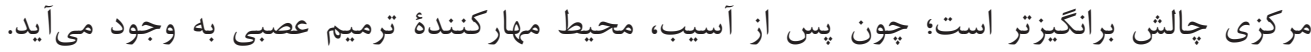

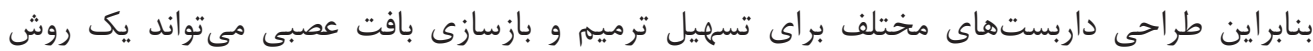

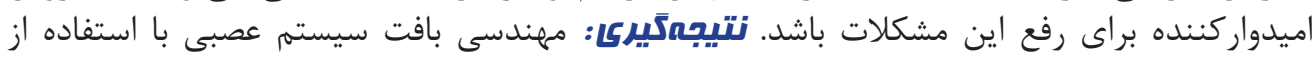

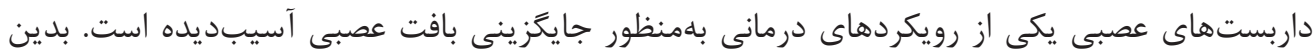

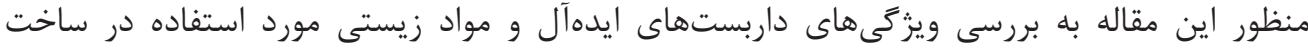

كليد وازمها:

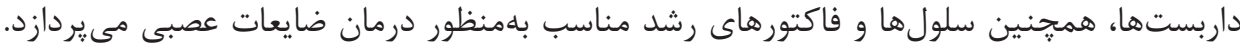

r.

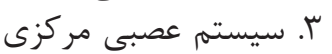

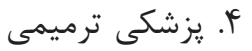

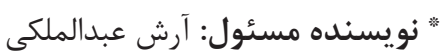
آدرس الكترونيكى: Abdolmalekiarash1364@gmail.com 
را بـراى بررسـى آسـيبهاى عصبـى ارائسه مى كنــد. سيسـتم

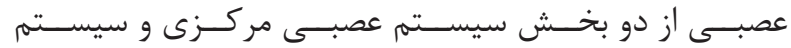

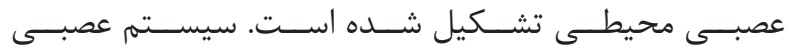

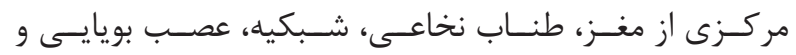

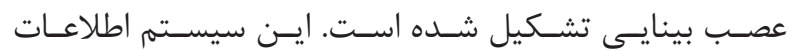

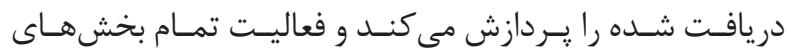

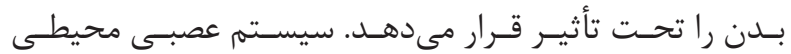

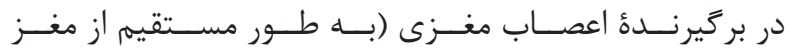

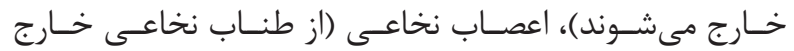

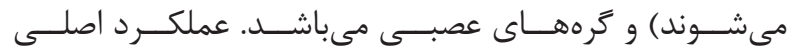

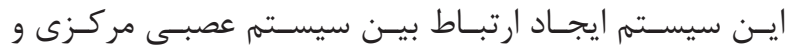

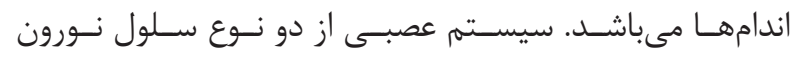

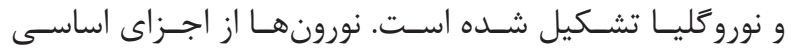

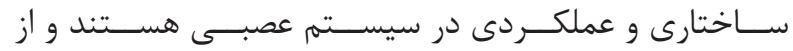

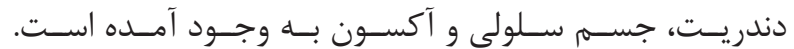

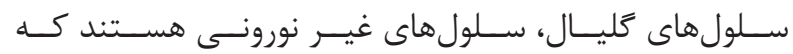

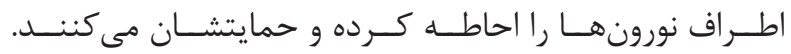

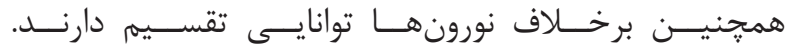

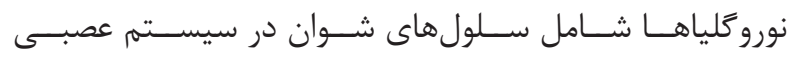

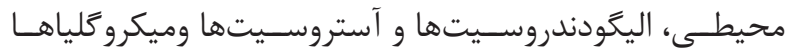

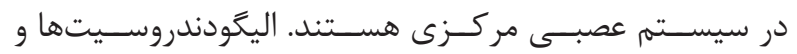

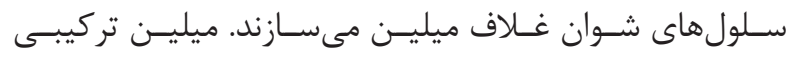

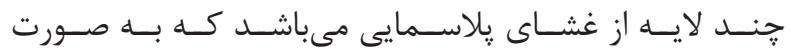

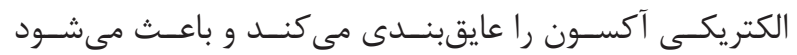

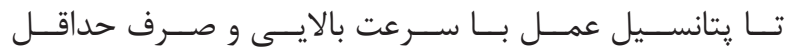

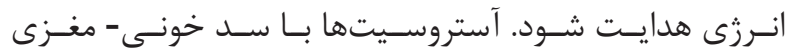

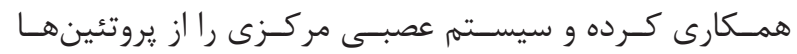

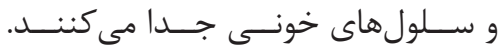

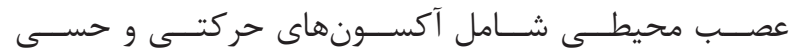

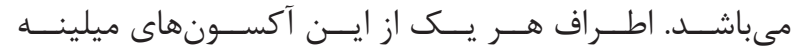

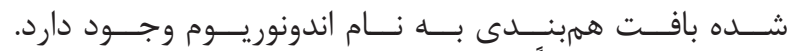

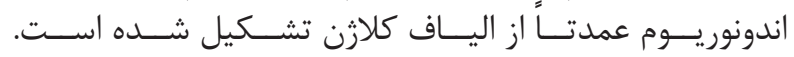

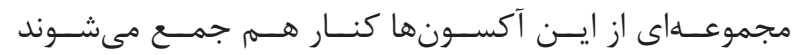

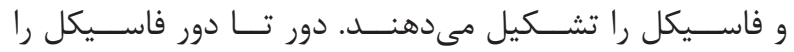

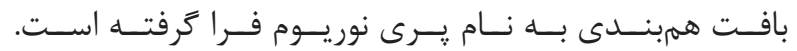

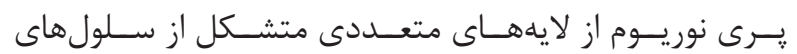

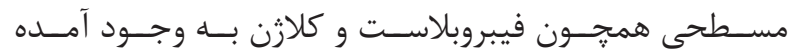

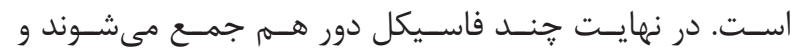

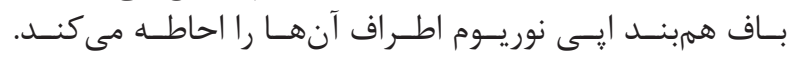

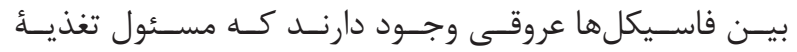

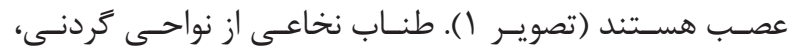

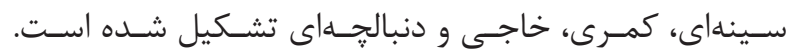

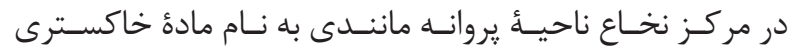

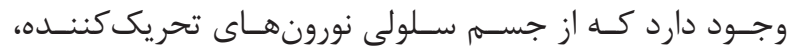

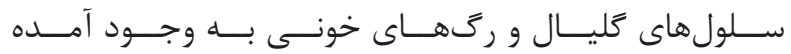

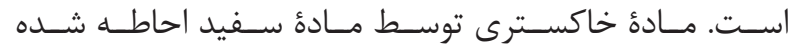

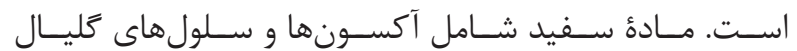

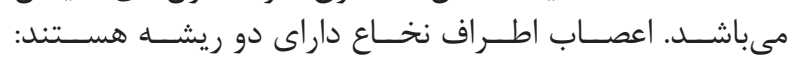

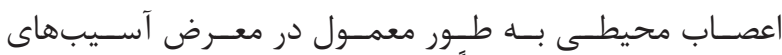

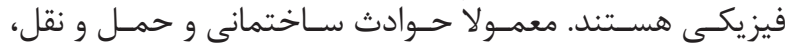

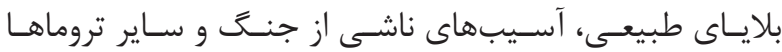

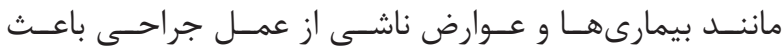

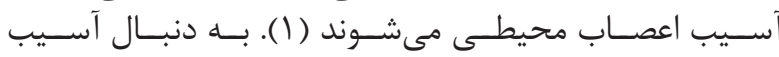

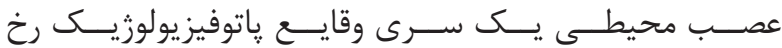

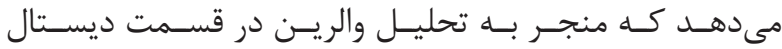

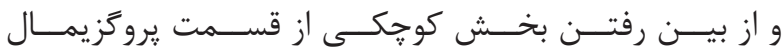

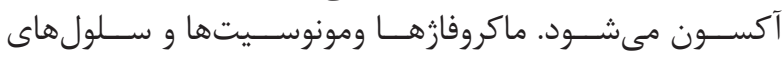

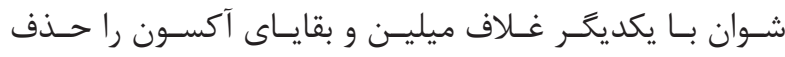

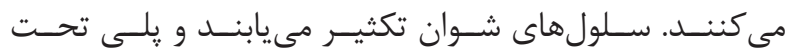

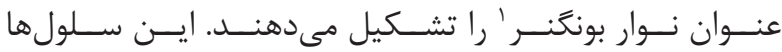

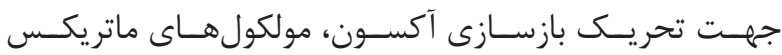

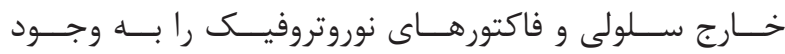

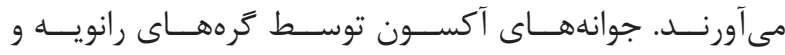

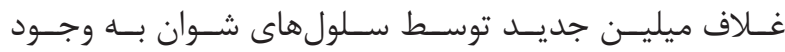

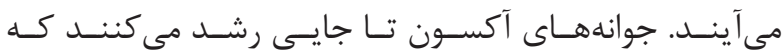

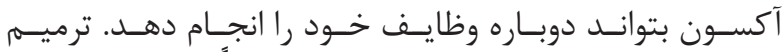

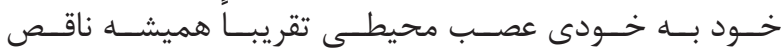

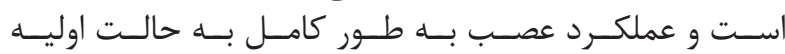

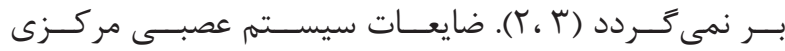

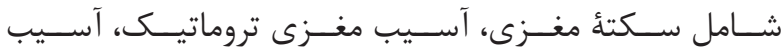

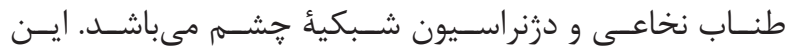

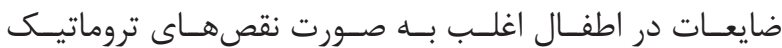

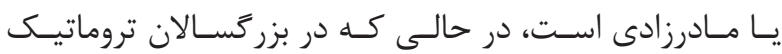

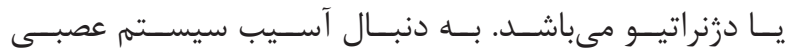

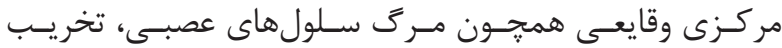

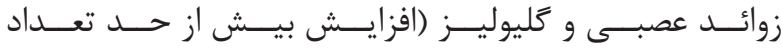

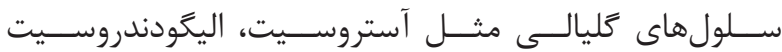

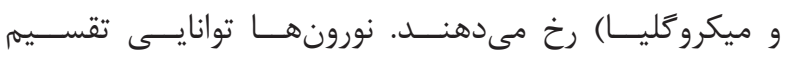

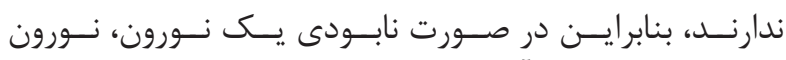

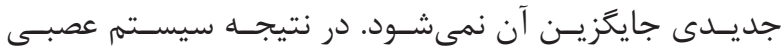

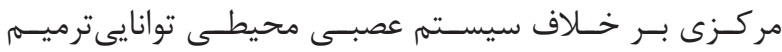

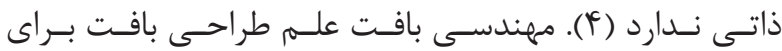

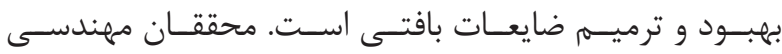

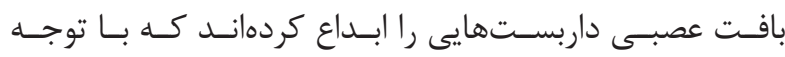

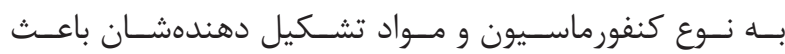

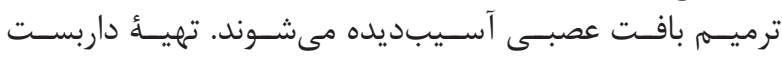

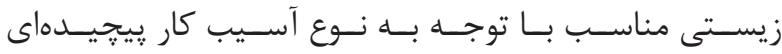

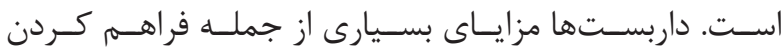

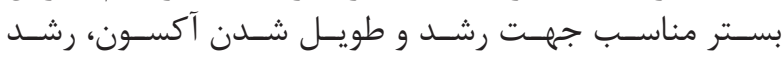

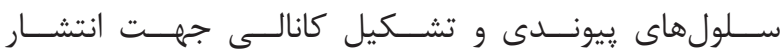

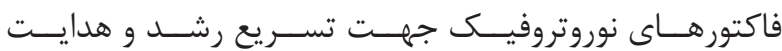

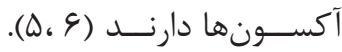
فيزيولوزى سيستم عصبى

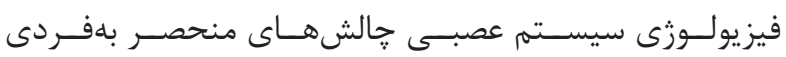




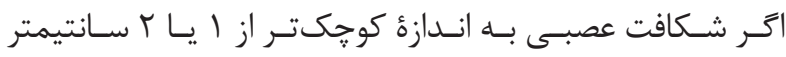

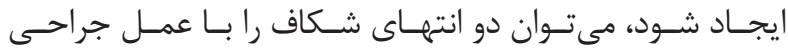

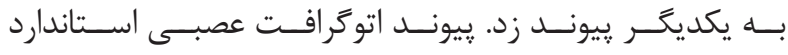

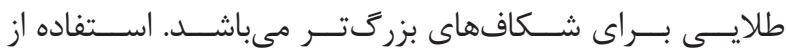

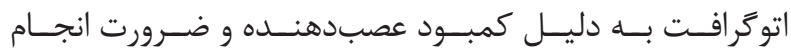

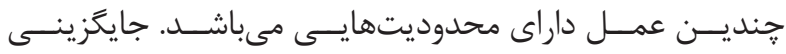

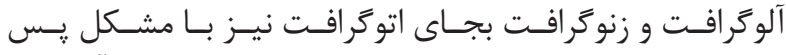

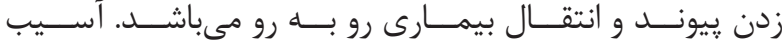

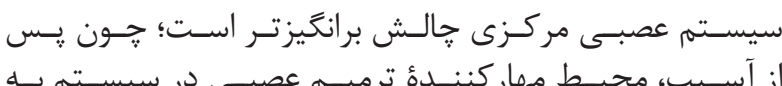

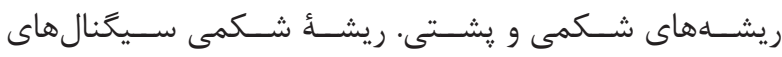

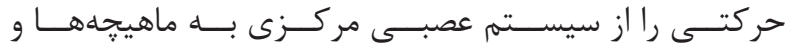

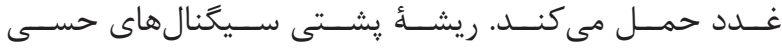

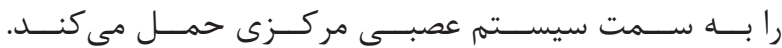

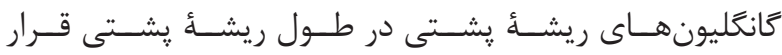

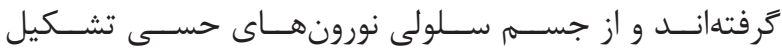

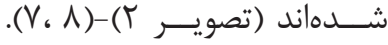
داربست عصبى در آســيبهاى ناشــى از ترومــاى سيســتم عصبـى محيطـى

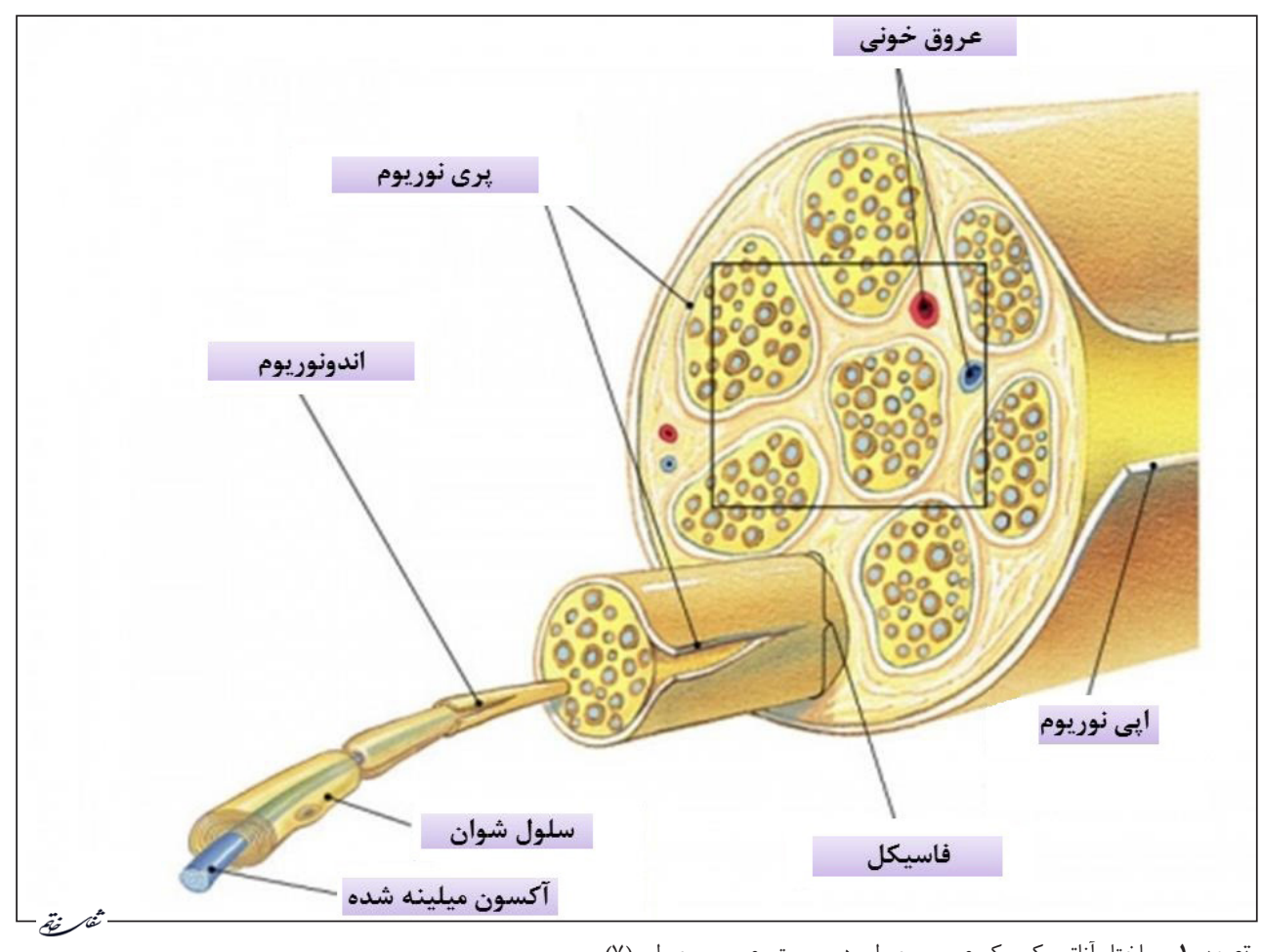

تصوير ا- ساختار آناتوميكى يك عصب محيطى در سيستم عصبى محيطى (V).

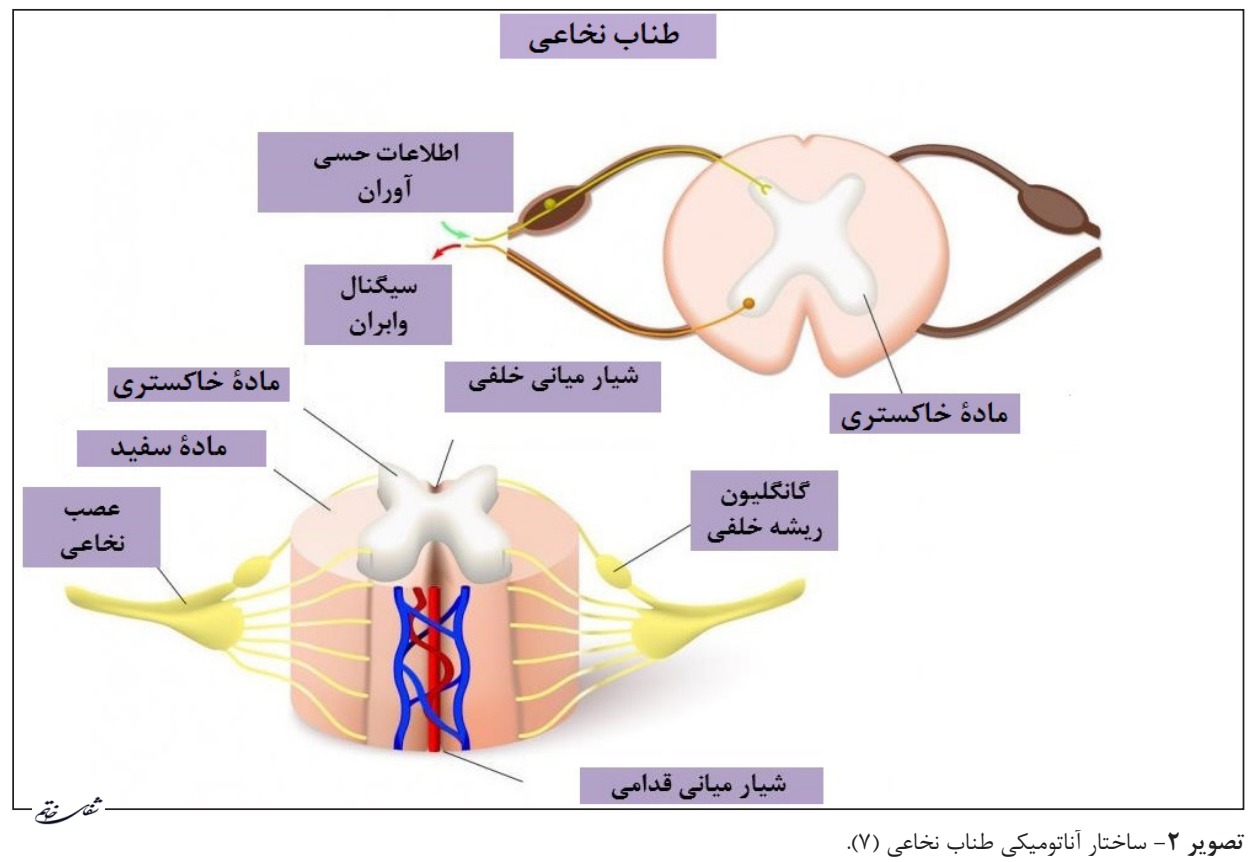




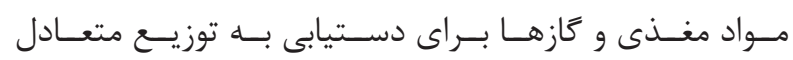

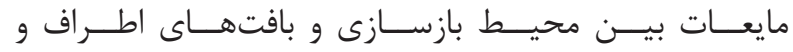

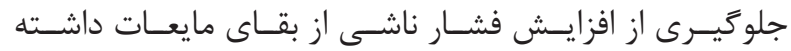

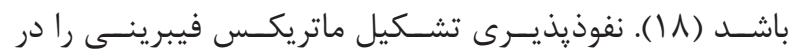

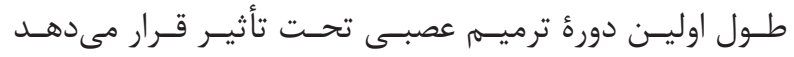

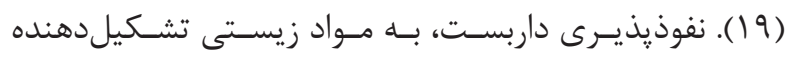

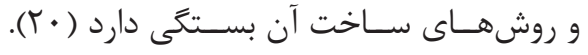

\section{ويزگى هاى زيست مكانيكى}

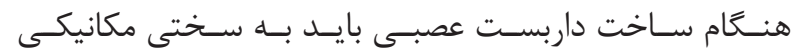

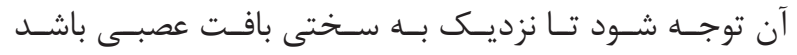

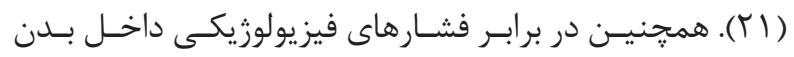

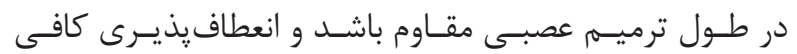

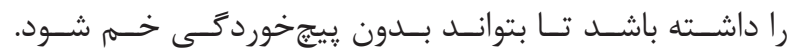

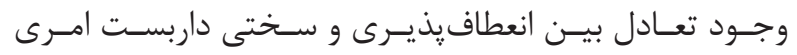

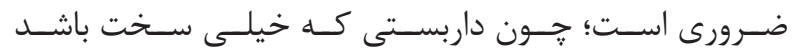

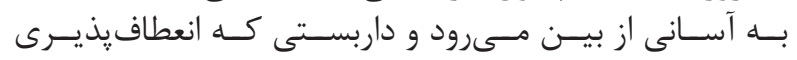

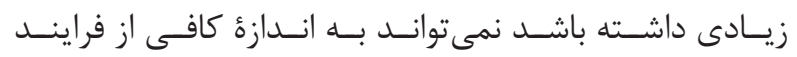

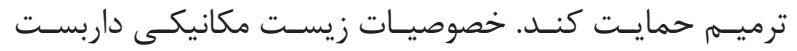

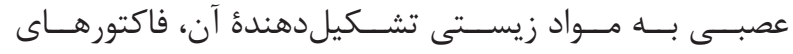

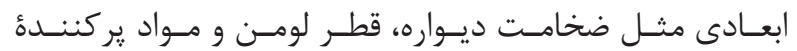

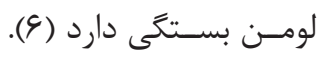

معمارى داربست

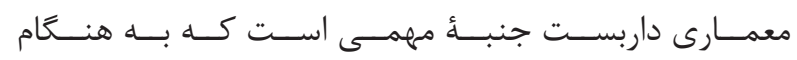

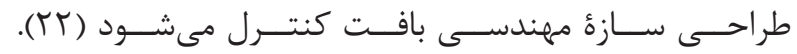

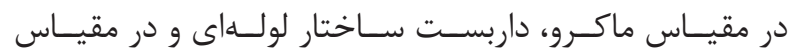

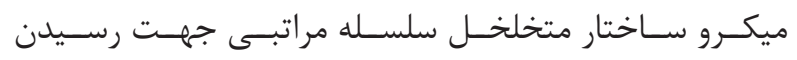

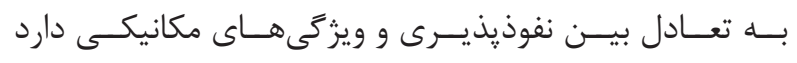

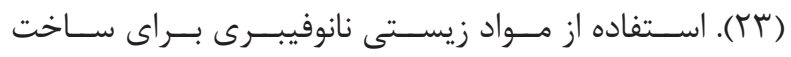

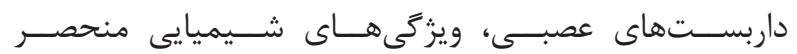

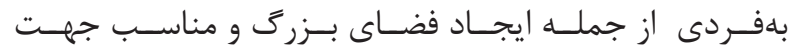

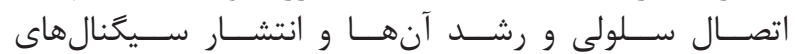

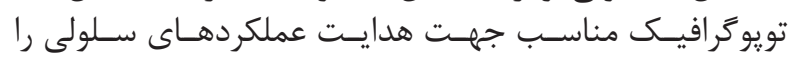

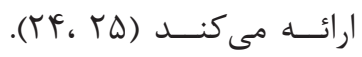

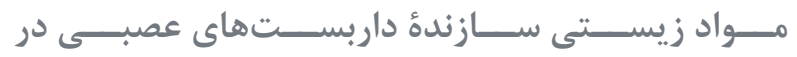

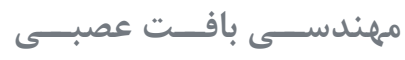

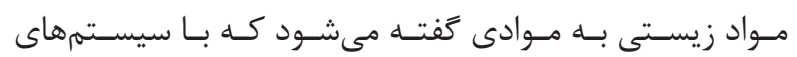

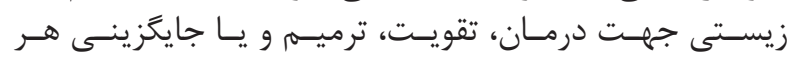

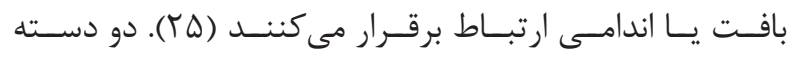

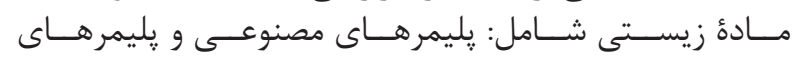

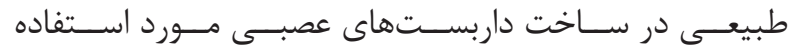

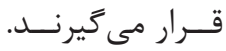

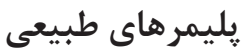

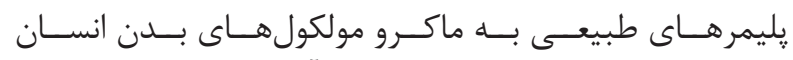

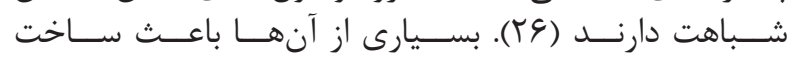

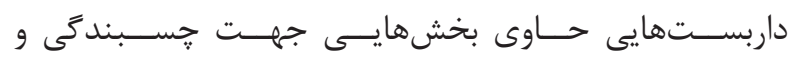

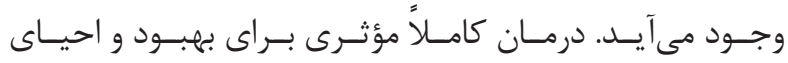

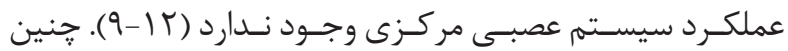

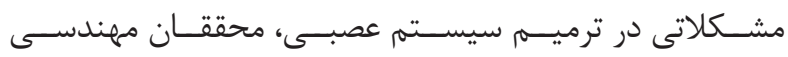

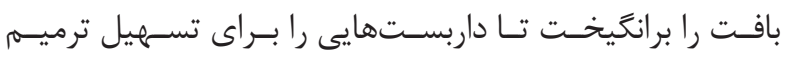

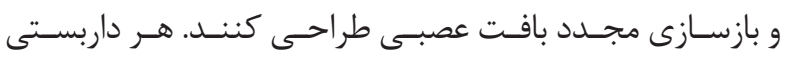

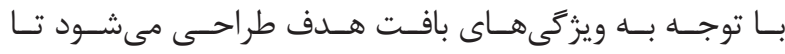

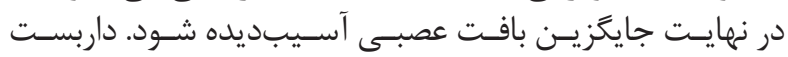

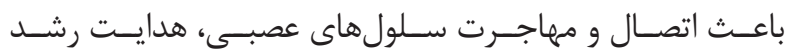

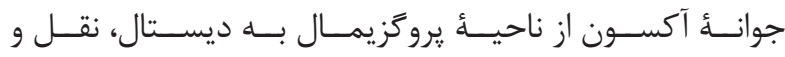

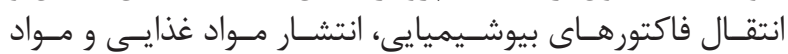

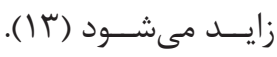

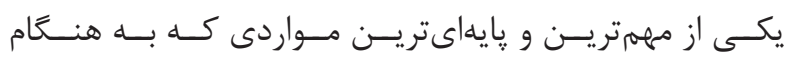

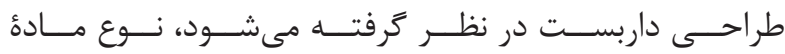

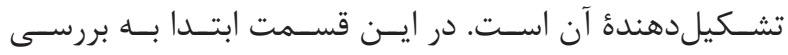

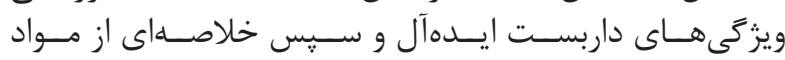

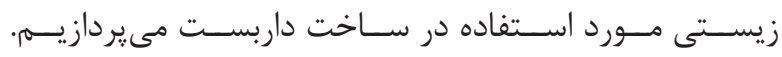

$$
\text { زيستى هاى داربست ايدهآل }
$$

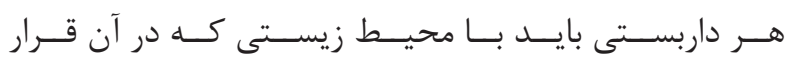

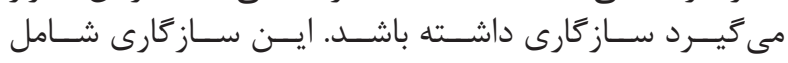

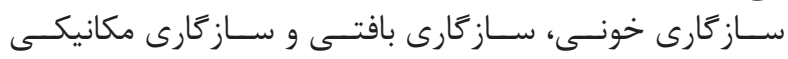

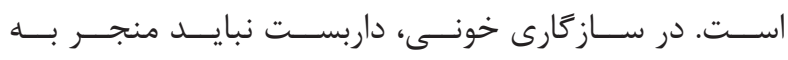

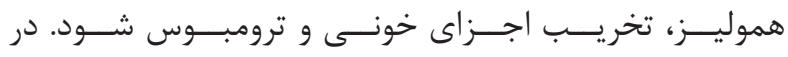

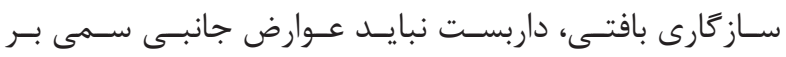

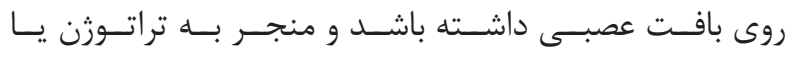

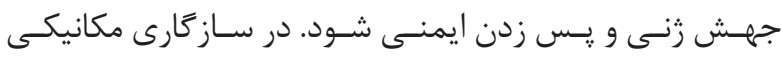

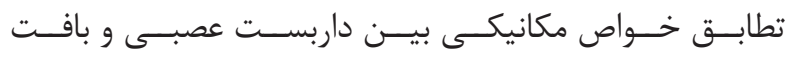

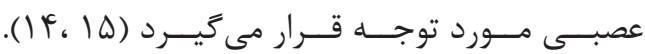

\section{زيست تخريب يذيرى}

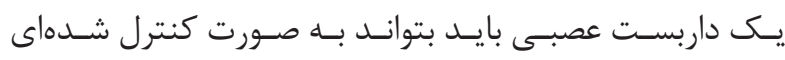

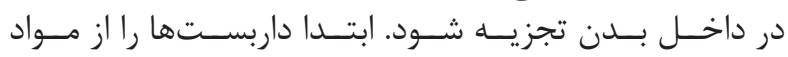

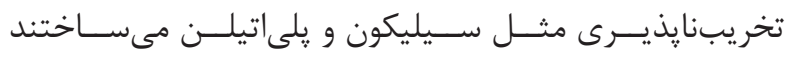

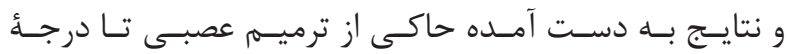

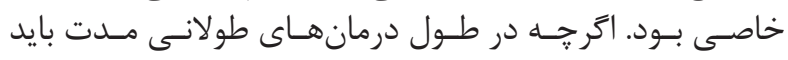

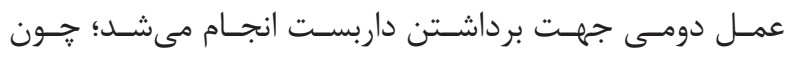

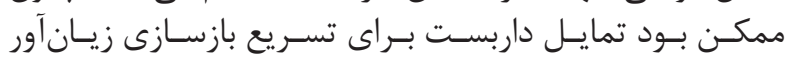

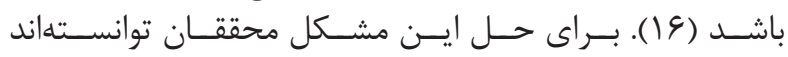

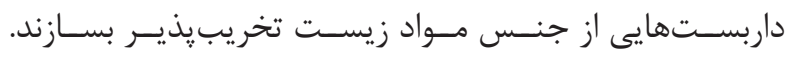

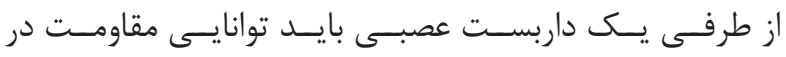

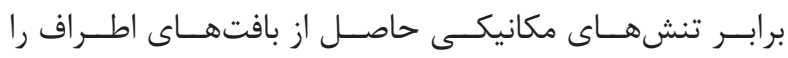

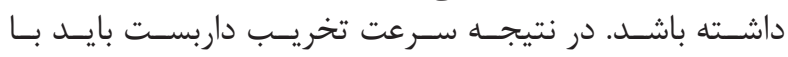

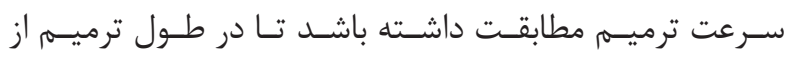

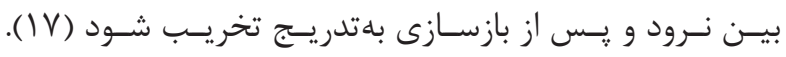

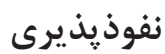

يـك داربسـت عصبـى بايـد نفوذيذيـرى كافـى جهـت تبـادل 


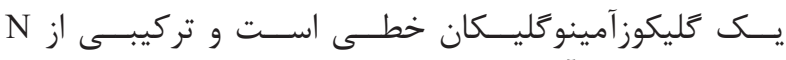

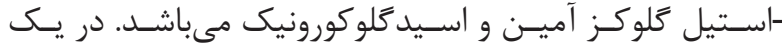

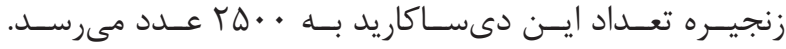

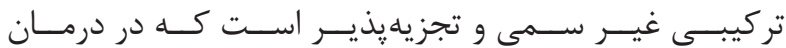

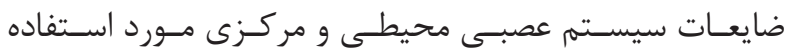

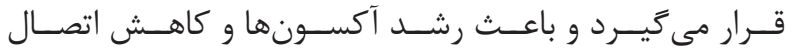

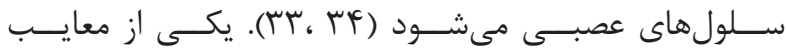

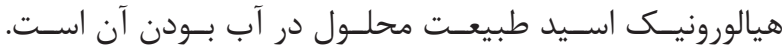

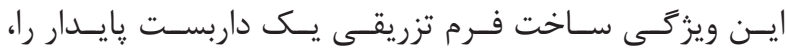

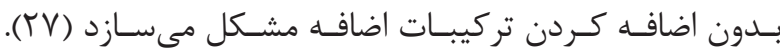

\section{فيبرونكتين}

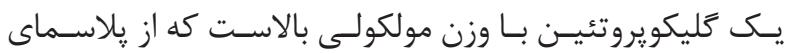

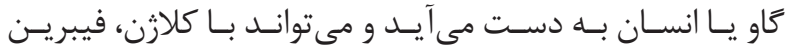

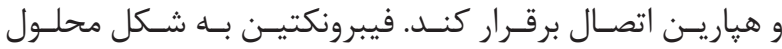

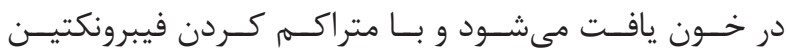

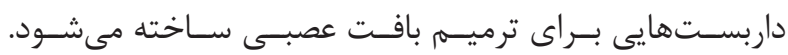

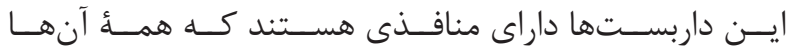

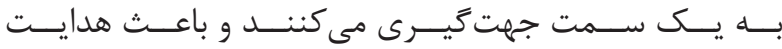

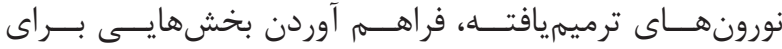

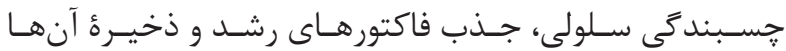

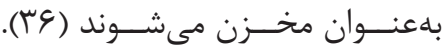

فيبر ين

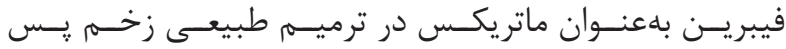

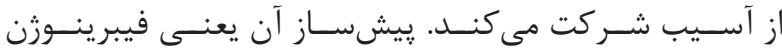

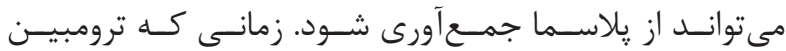

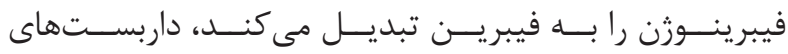

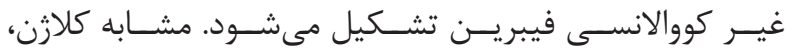

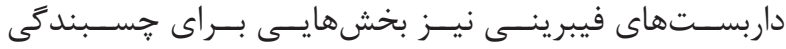

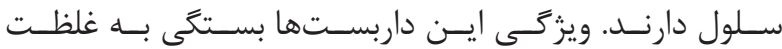

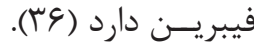

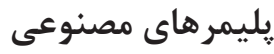

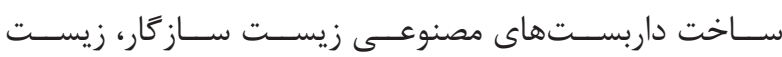

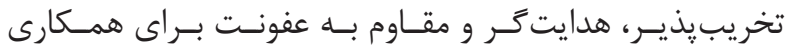

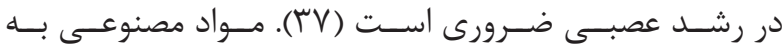

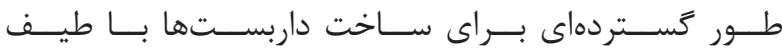

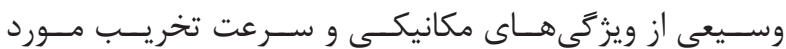

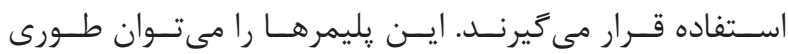

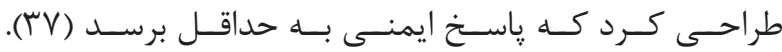

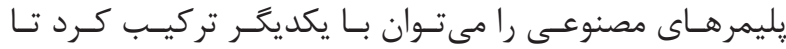

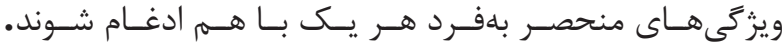

\section{بليلى اتيلن كليكول}

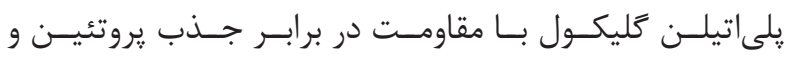

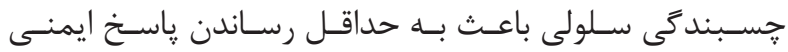

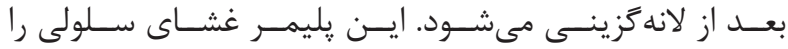

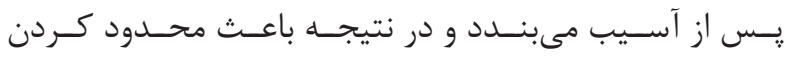

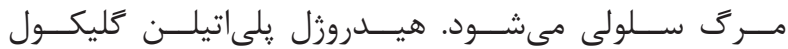

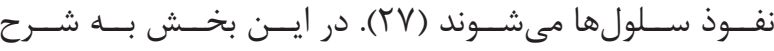

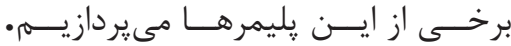

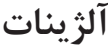

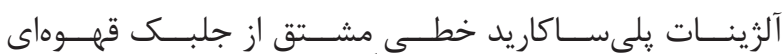

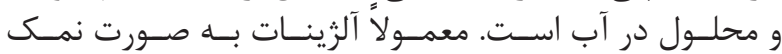

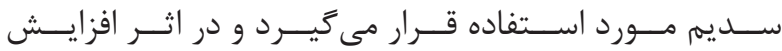

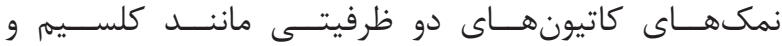

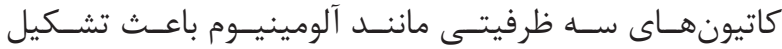

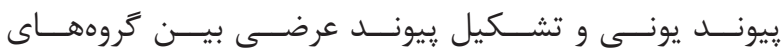

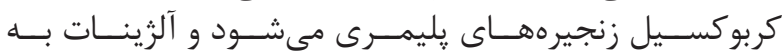

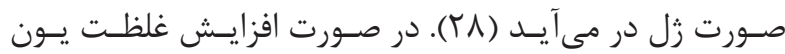

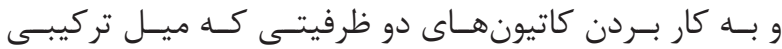

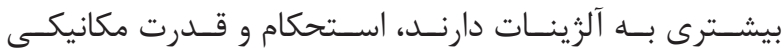

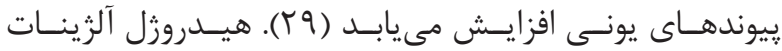

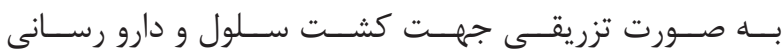

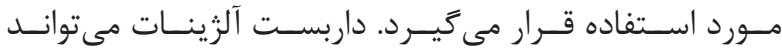

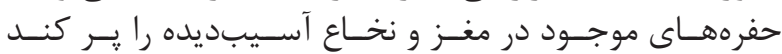

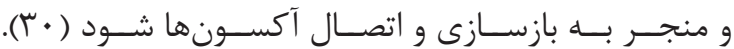

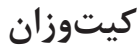

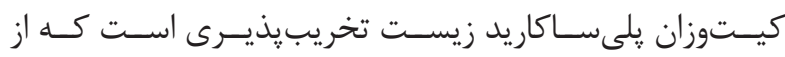

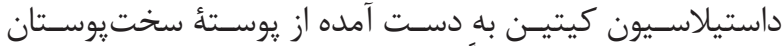

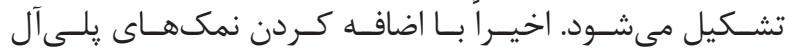

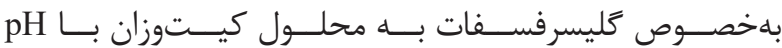

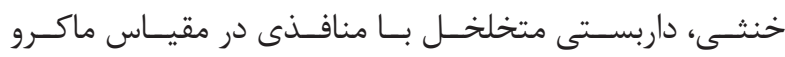

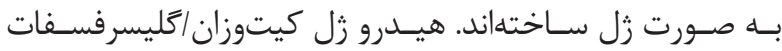

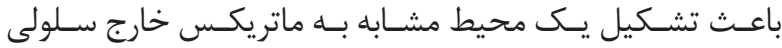

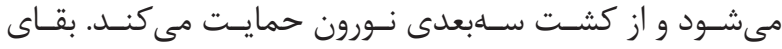

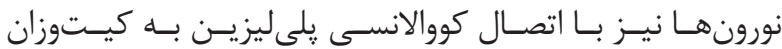

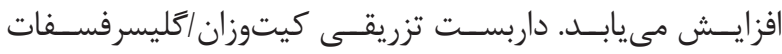

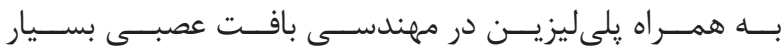
ير كاربـرد اسـت (·) (广).

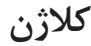

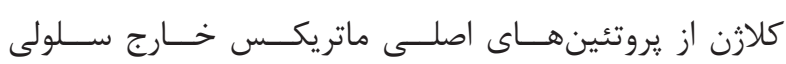

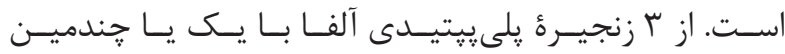

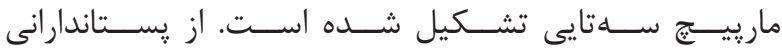

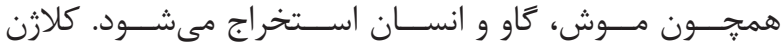

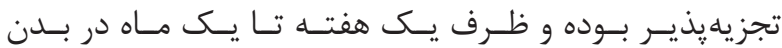

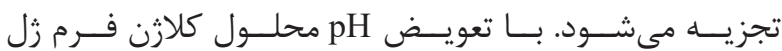

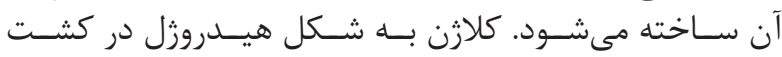

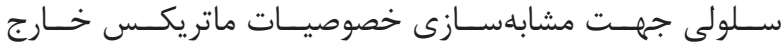

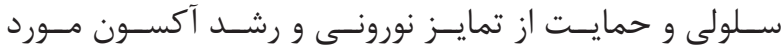

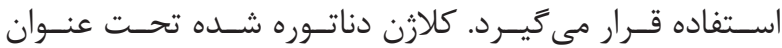

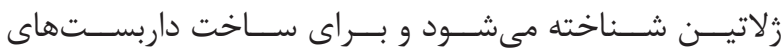

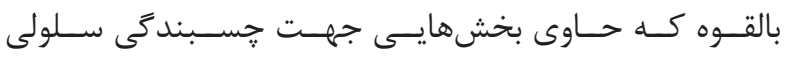

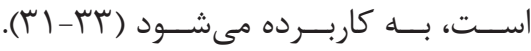


شـده، يلـى ريــرول آلـرزى، تـب، جهــش، هموليـز و سـميتى

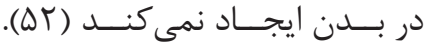

فاكتور هاى رشد

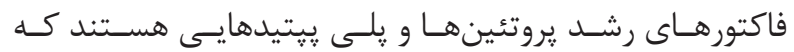

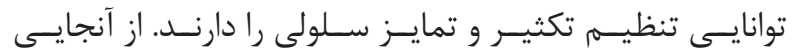

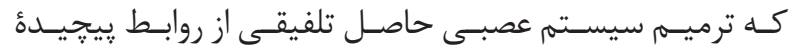

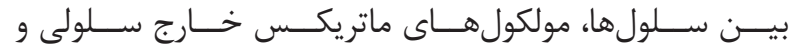

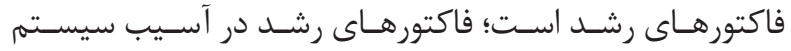

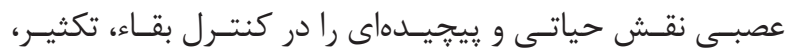

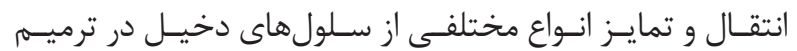

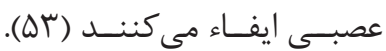

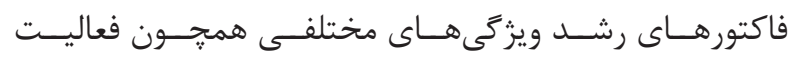

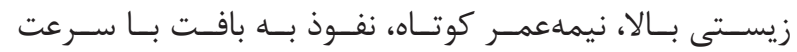

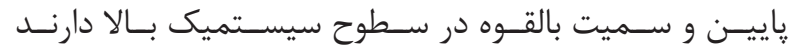

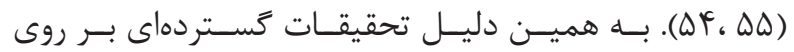

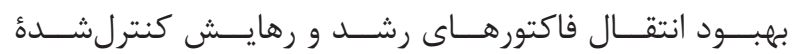

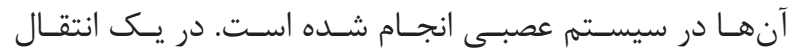

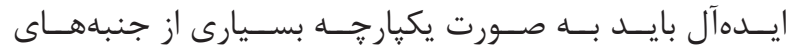

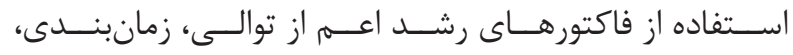

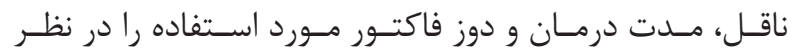

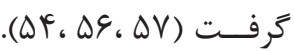

\section{فاكتور هاى نوروتروفيك}

فاكتورهـاى رشــد در سيسـتم عصبى تحـت عنـوان فاكتورهاى

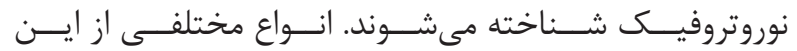

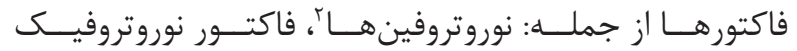

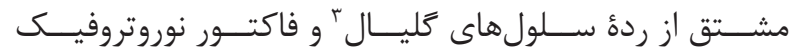

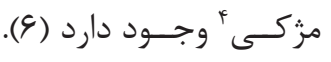

\section{نوروتروفينها}

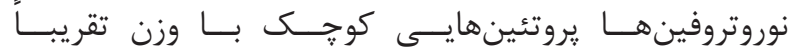

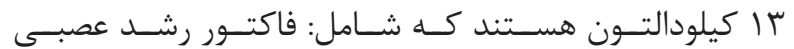
(NGF)

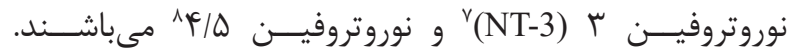

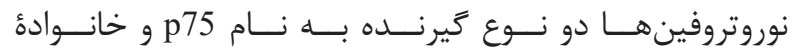

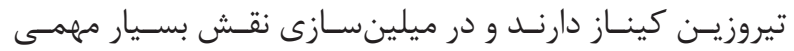

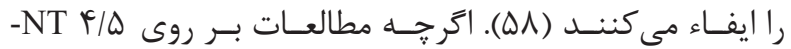

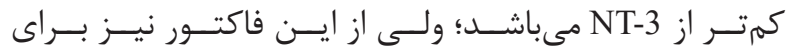

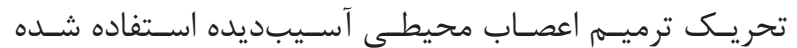

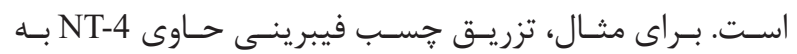

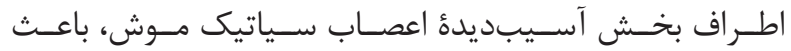

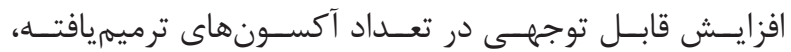

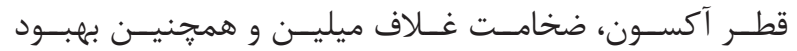

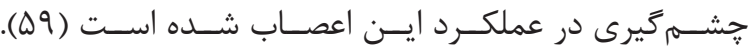

${ }^{2}$ Neurotrophin

${ }^{3}$ Glial cell line-derived neurotrophic factor

${ }^{4}$ Ciliary neurotrophic factor

${ }^{5}$ Nerve growth factor

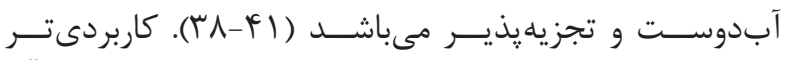

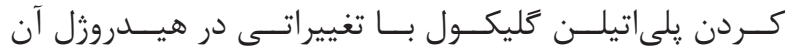

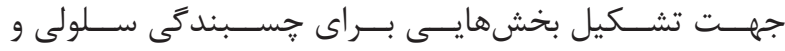

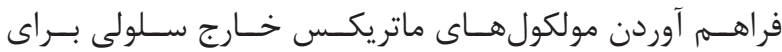

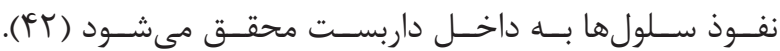

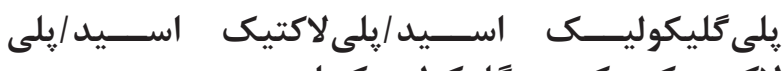

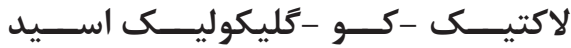

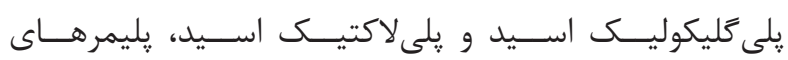

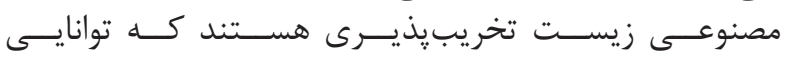

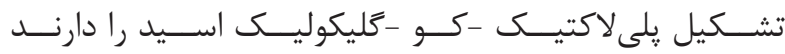

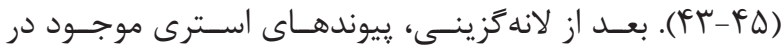

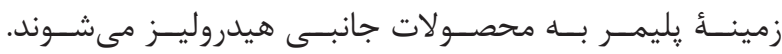

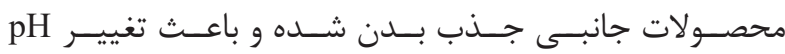

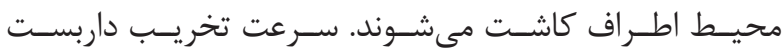

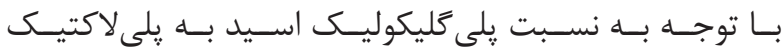

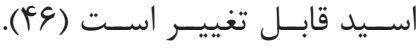

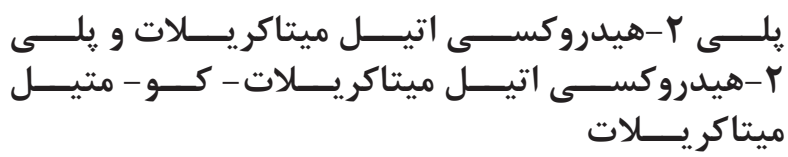

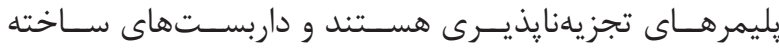

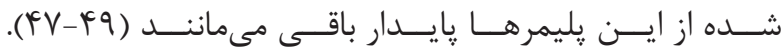

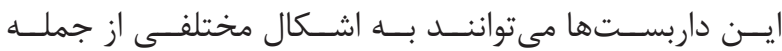

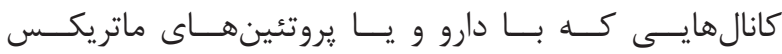

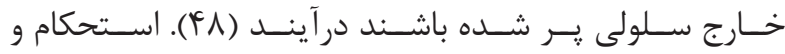

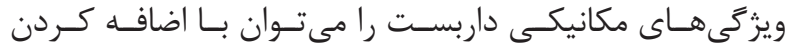

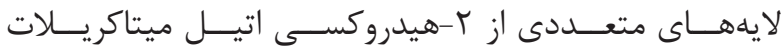

تغييــر داد ( • ()).

يلى : ييرول

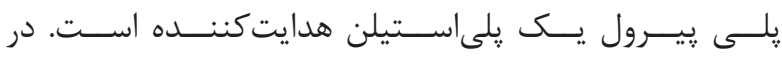

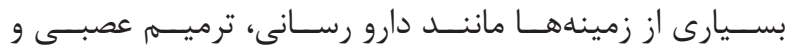

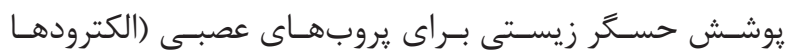

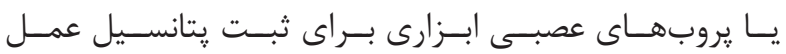

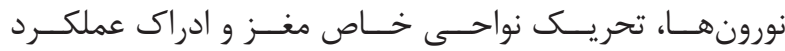

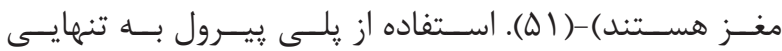

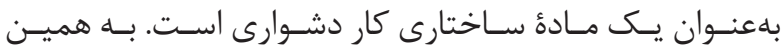

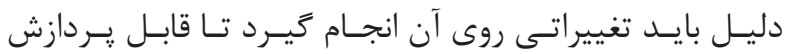

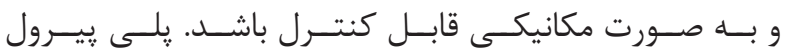

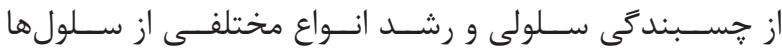

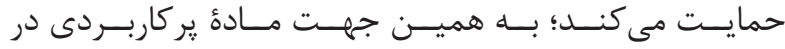

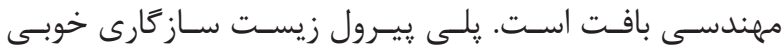

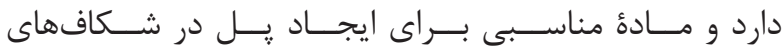

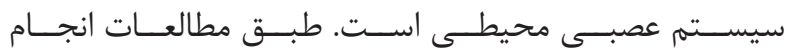

${ }^{6}$ Brain-derived neurotrophic factor

${ }^{7}$ Neurotrophin-3

${ }^{8}$ Neurotrophin- $4 / 5$ 


\section{جدول ا- انواع نوروتروفين و سلولهاى هدف آنها در سيستم عصبى مركزى و محيطى (·9).}

\begin{tabular}{|c|c|c|}
\hline 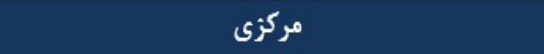 & محيطى & ن توروتروفين \\
\hline 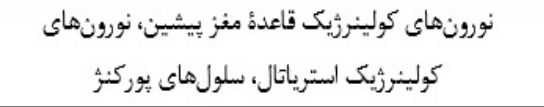 & نورونهاى سمياتيك، نورونهاى حسى: & فاكتور رشد عصبى \\
\hline 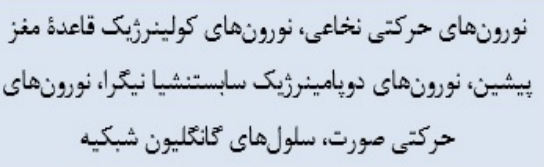 & نورونهاى حسى، نورونهاى ريشهُ & فاكتور نوروتروفيك مشتقيده از مغز \\
\hline نورونهاى كولينرئيك قاعدة مغز يِيشين، نورونهاى لوكوس & نورونهاى سمياتيك، نورونهاى حسى & ن نوروتروفين † \\
\hline 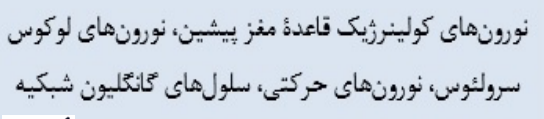 & نورونهاى سمياتيك، نورونهاى حسى: & 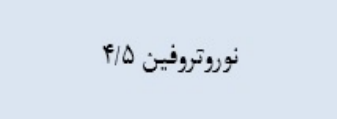 \\
\hline
\end{tabular}

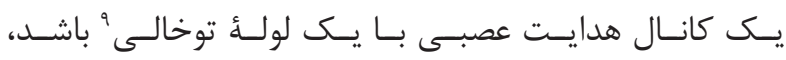

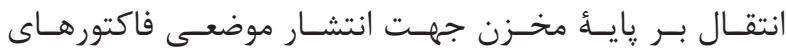

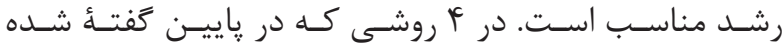

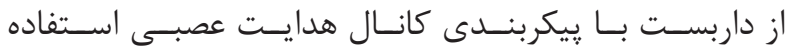
شــده اسـت

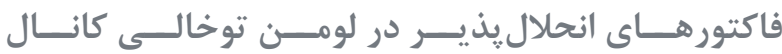

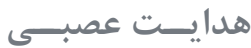

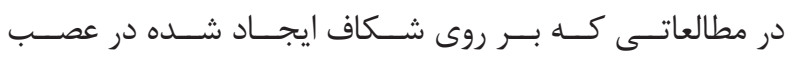

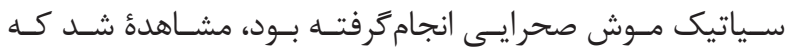

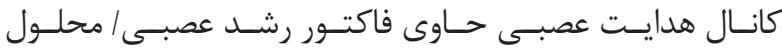

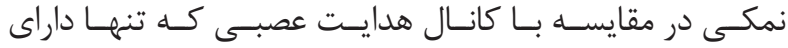

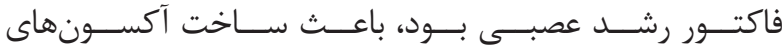

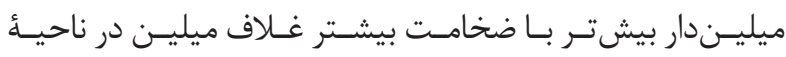

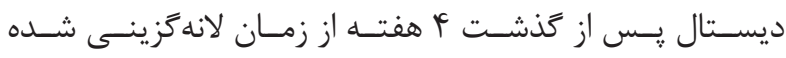

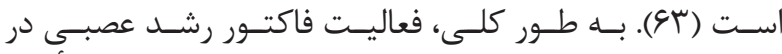

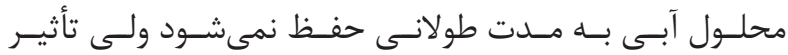

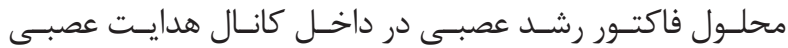

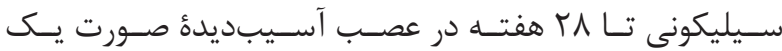

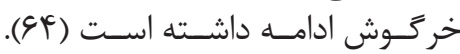

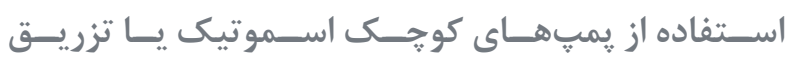
مكـــر

بويـد و گَـوردون 'ل بـراى رهايـش فاكتـور نوروتروفيـك مشـتق

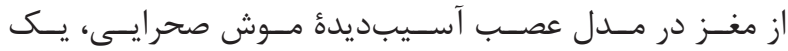

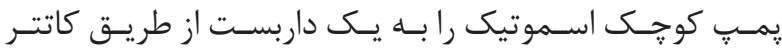

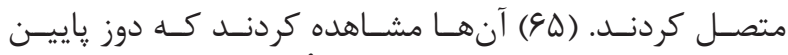
BDNF

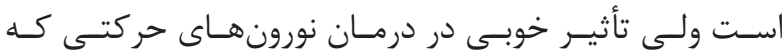

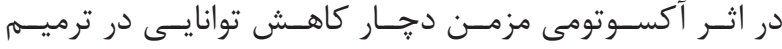

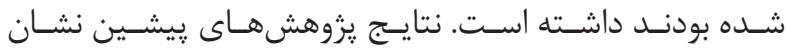

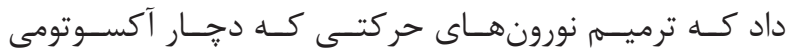

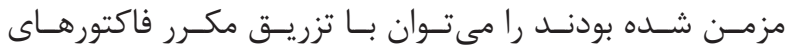

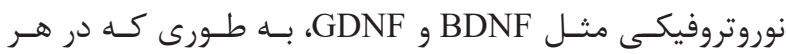

فاكتـــــور نوروتروفيـــــ مشـــــتق از ردهُ ســــلول هاى كَليــال

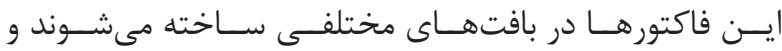

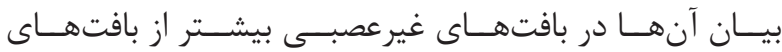

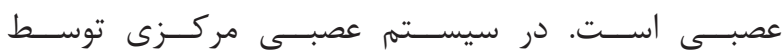

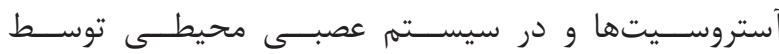

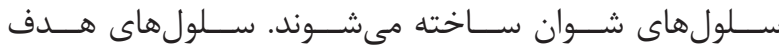

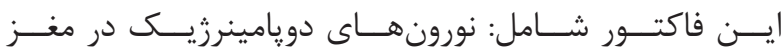

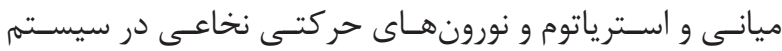

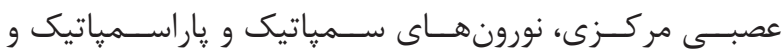

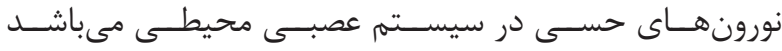

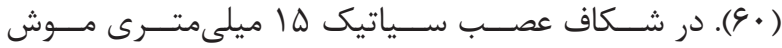

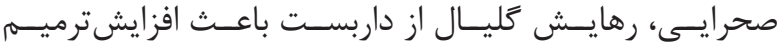

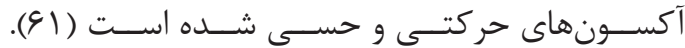
فاكتور نوروتروفيك مثزى

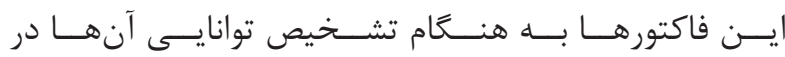

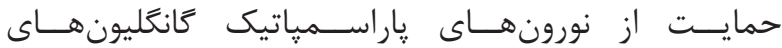

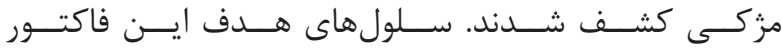

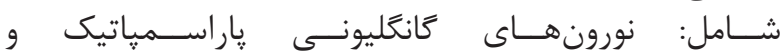

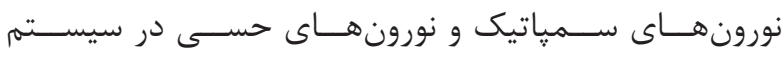

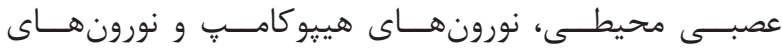

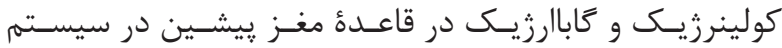

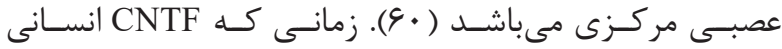

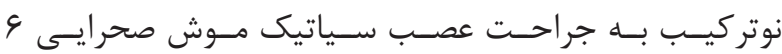

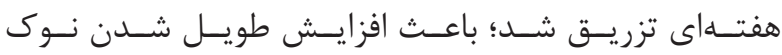

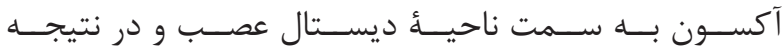

$$
\begin{aligned}
& \text { ترميــم آكســون گرديــــ (GT). } \\
& \text { انتقال فاكتور هاى رشد }
\end{aligned}
$$

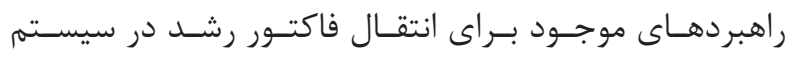

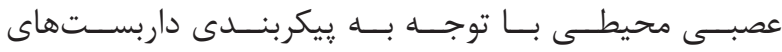

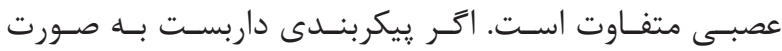

\footnotetext{
${ }^{9}$ Single hollow lumen nerve guidance conduit

${ }^{10}$ Boyd and Gordon
} 


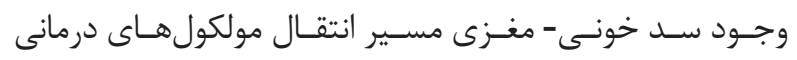

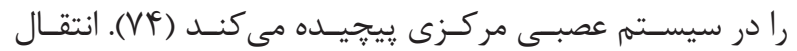

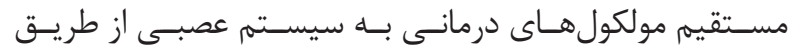

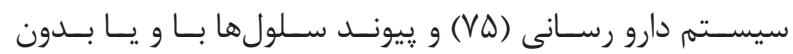

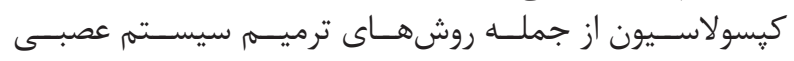

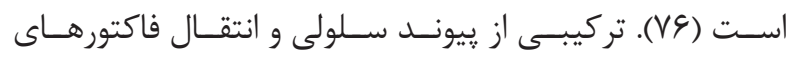

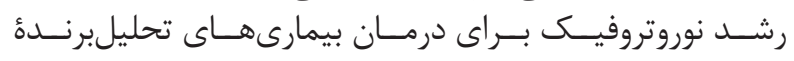

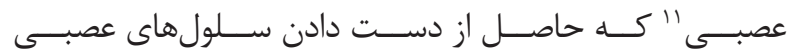
مىباشــند، مفيــد اسـت (VV، VN).

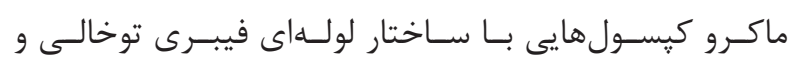

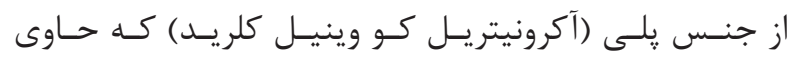

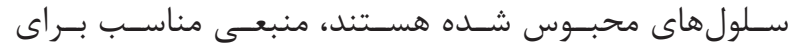

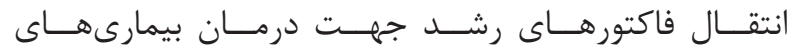

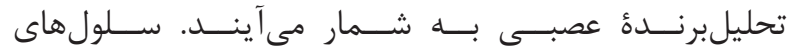

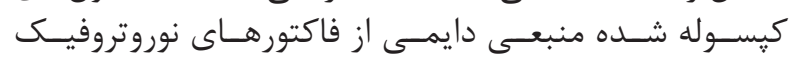

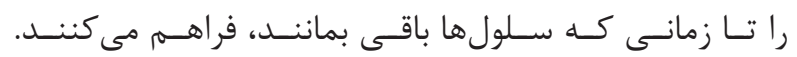

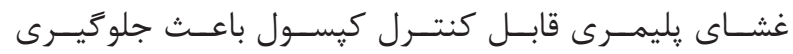

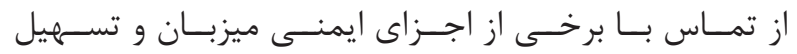

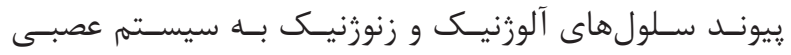

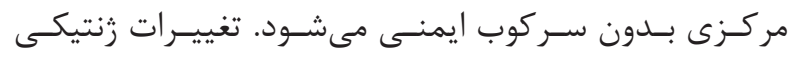

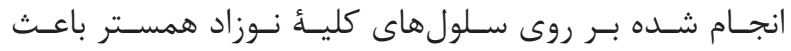

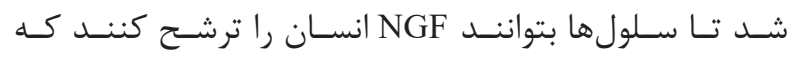

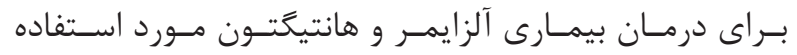

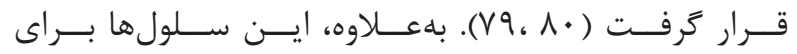

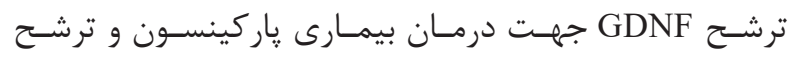

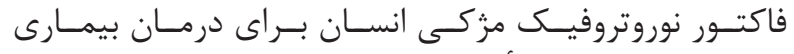

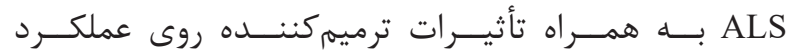

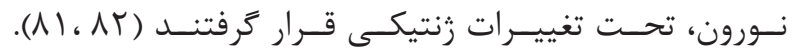

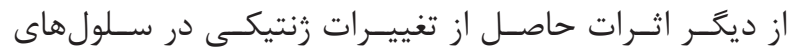

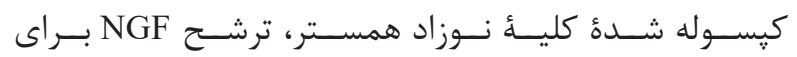

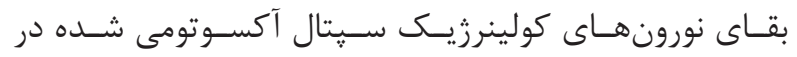

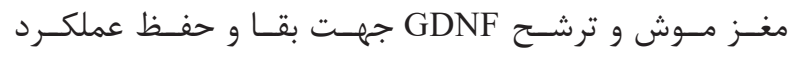

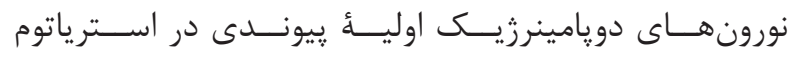

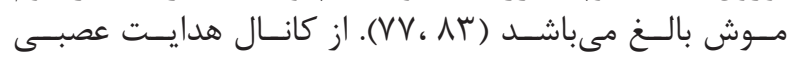

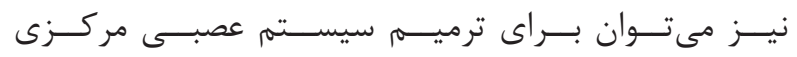

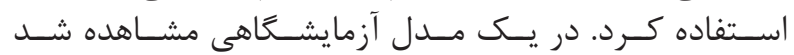

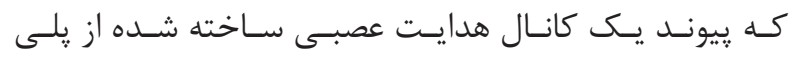

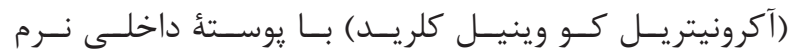

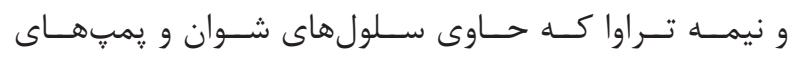

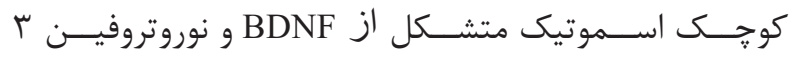

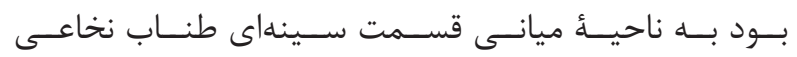

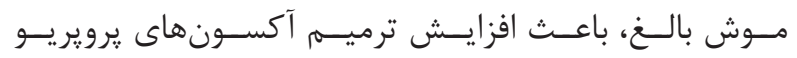

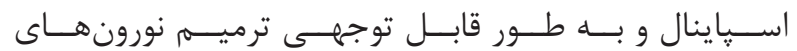

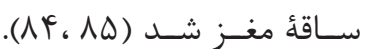

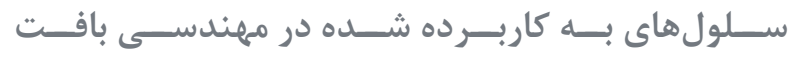
عصبــ

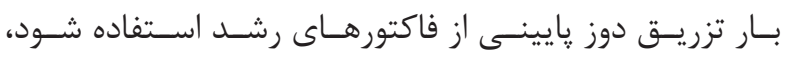

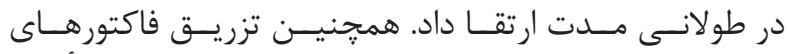

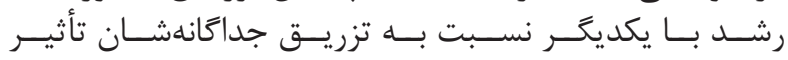

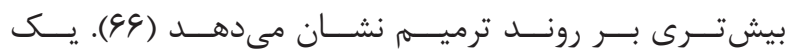

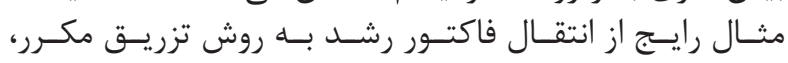

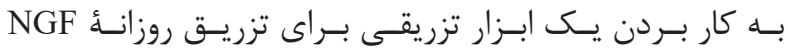

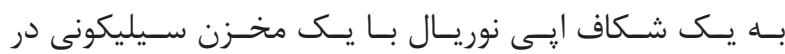

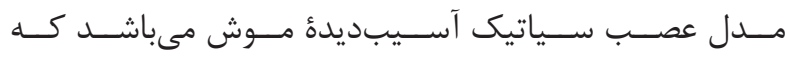

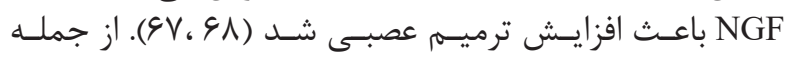

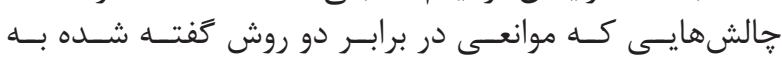

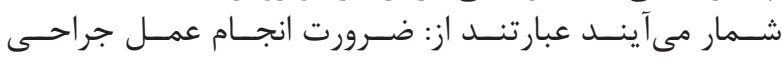

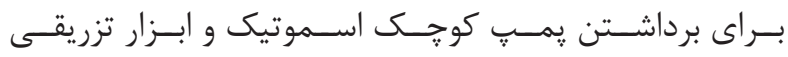

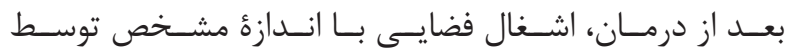

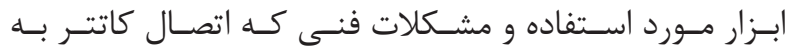

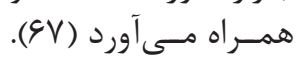
انتقال از طريق ديواره داربست

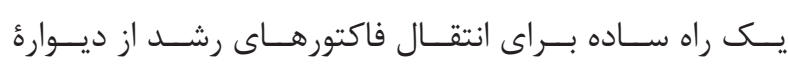

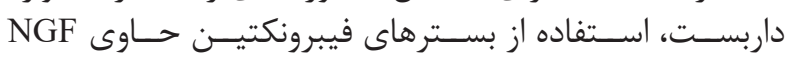

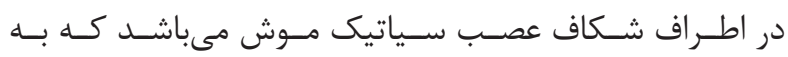

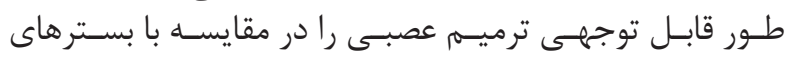

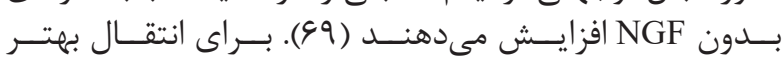

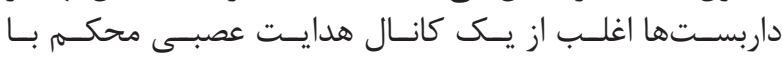

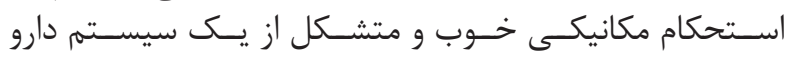

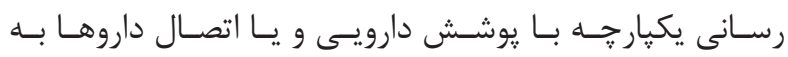

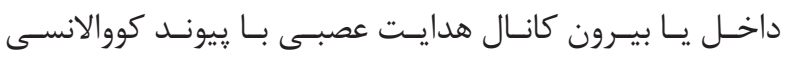

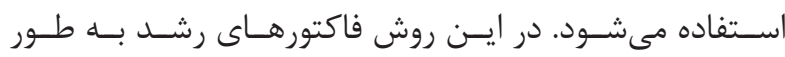

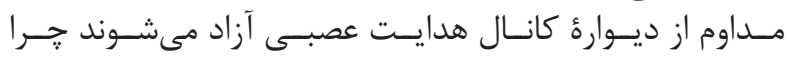

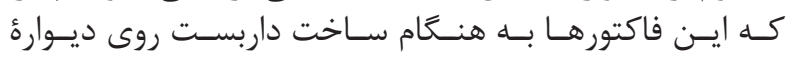

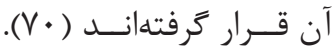
انتقال از طريق ميكروسفرها

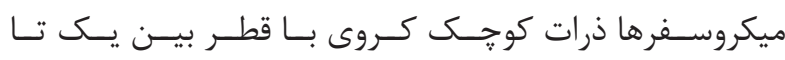

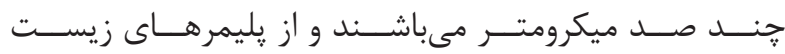

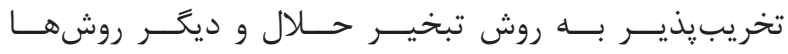

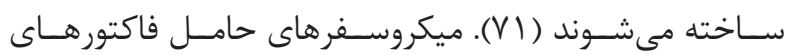

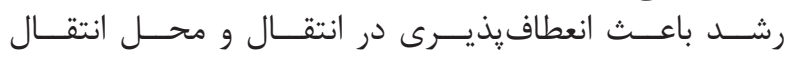

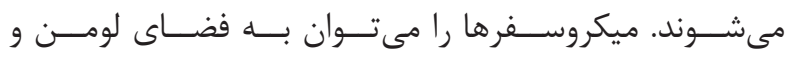

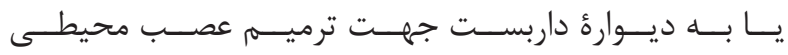

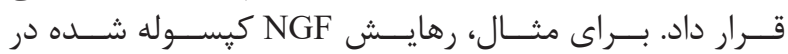

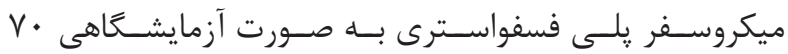

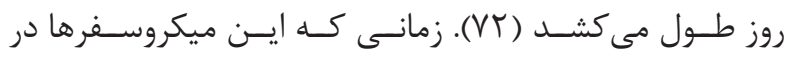

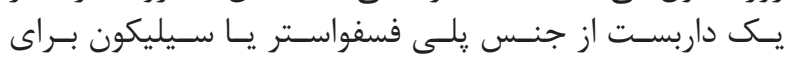

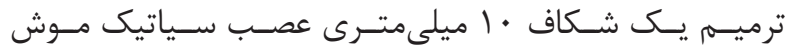

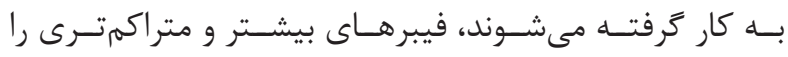

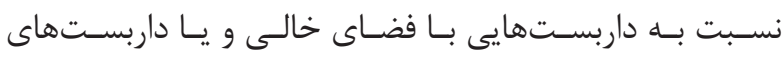

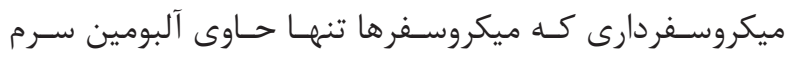

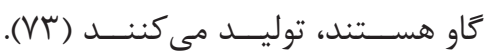




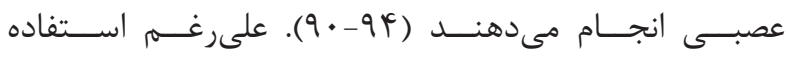

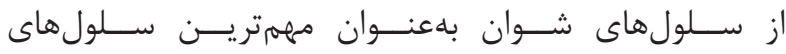

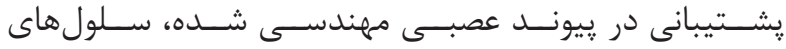

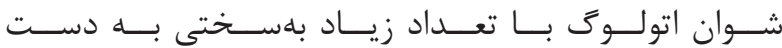

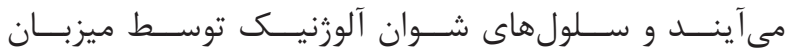

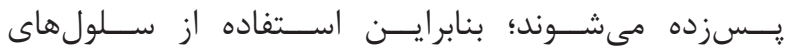

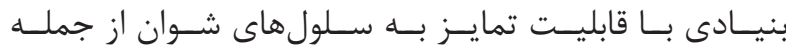

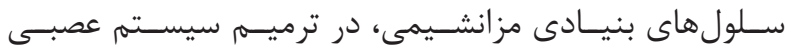

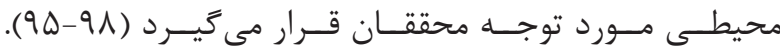

\section{سلولها بنيادى رويانى}

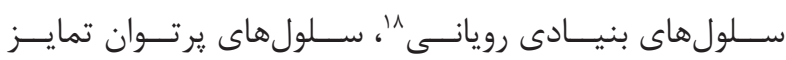

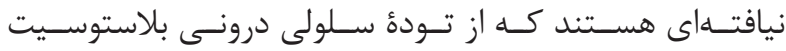

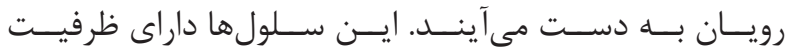

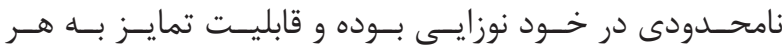

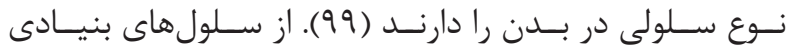

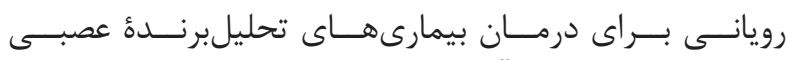

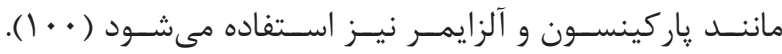

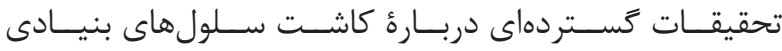

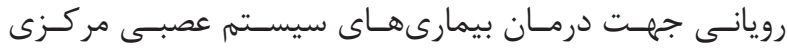

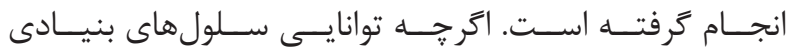

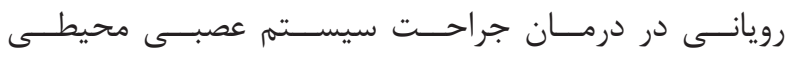

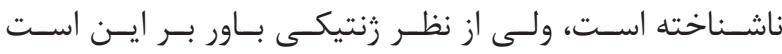

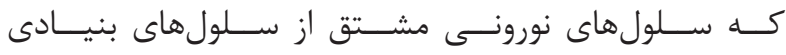

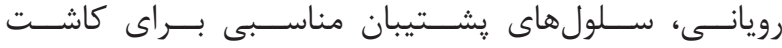

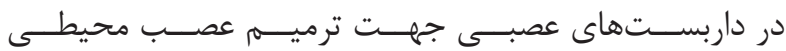

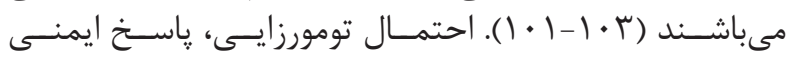

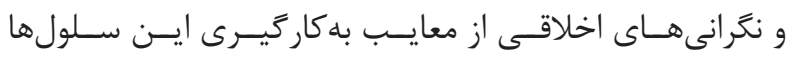

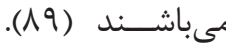

\section{ســـلول هاى بنيـــادى عصبـــى و ســـلول هاى ييشـــــــاز

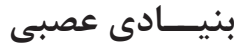

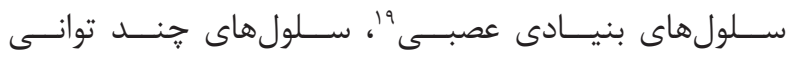

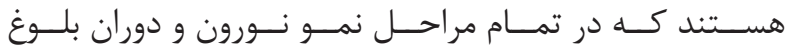

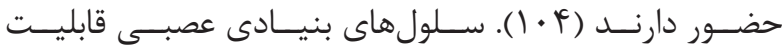

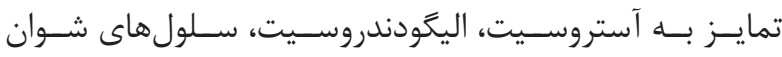

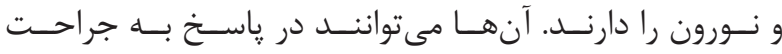

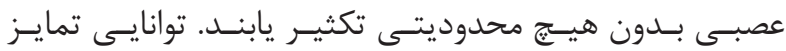

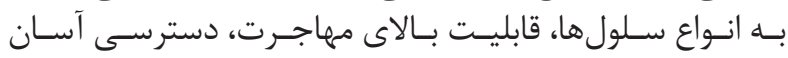

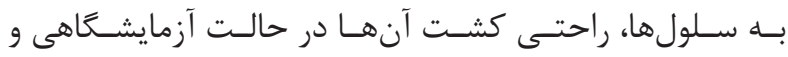

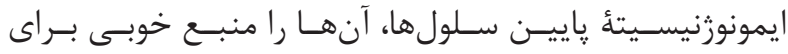

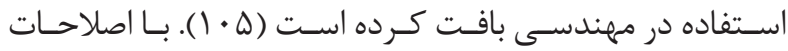

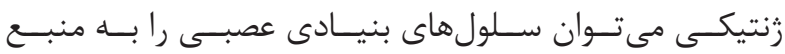

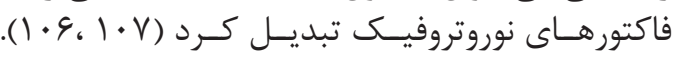

سـلول هاى بنيـادى عصبـى كاشـته شـده در داربسـت عصبـى

\section{${ }^{12}$ Autologous}

${ }^{13}$ Allogenic

${ }^{14}$ Xenogeneic

${ }^{15}$ Apligraft

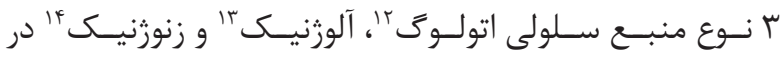

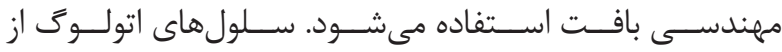

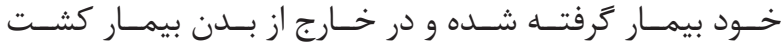

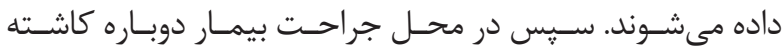

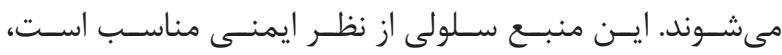

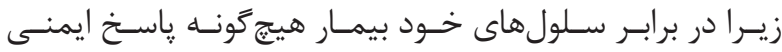

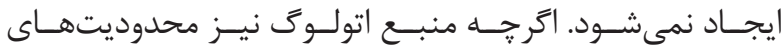

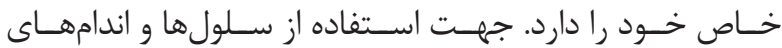

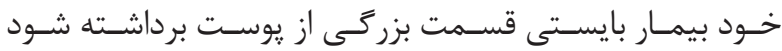

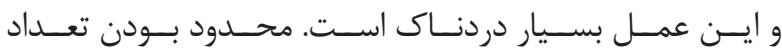

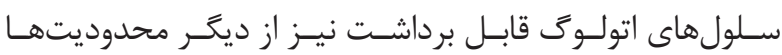

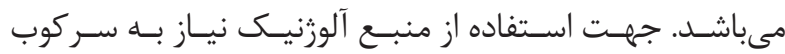

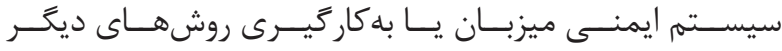

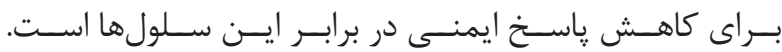

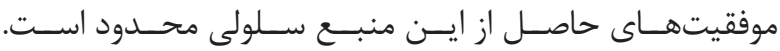

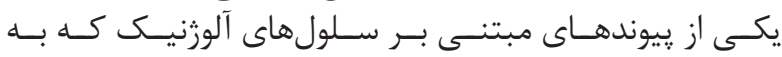

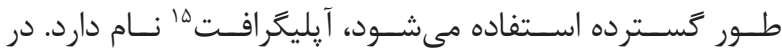

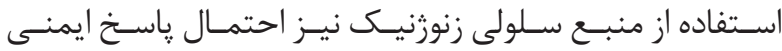

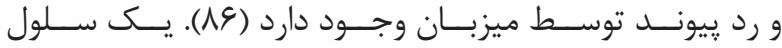

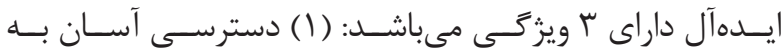

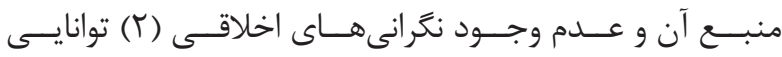

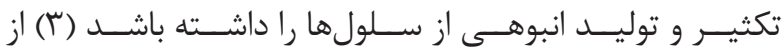

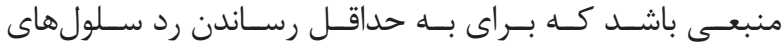

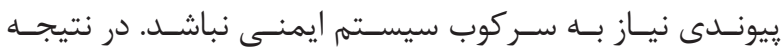

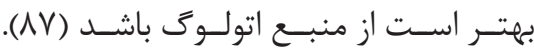

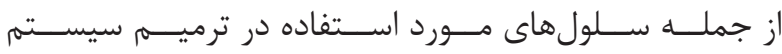

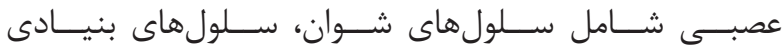

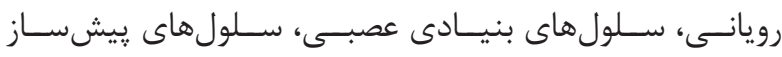

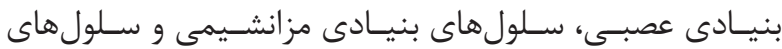

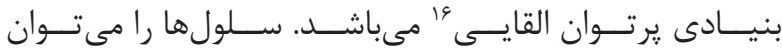

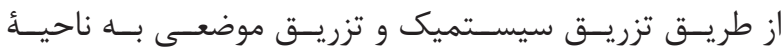

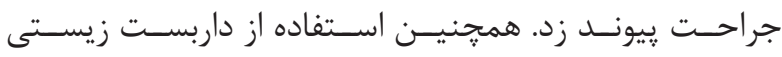

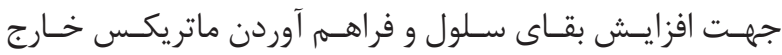

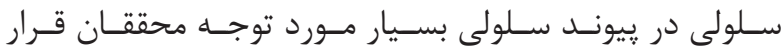

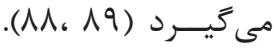

سلول هاى شوان

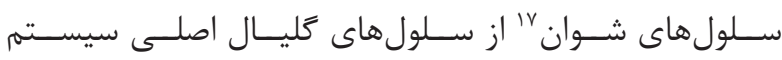

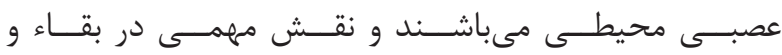

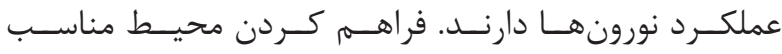

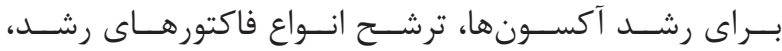

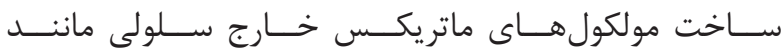

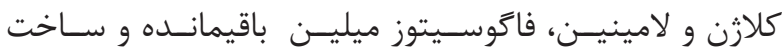

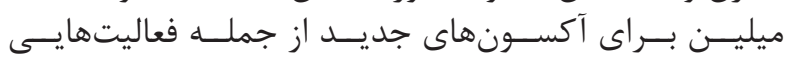

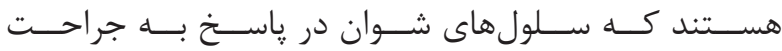

\footnotetext{
${ }^{16}$ Induced Pluripotent stem cell

${ }^{17}$ Schwann cell

${ }^{18}$ Embryonic stem cell

${ }^{19}$ Neural stem cell
} 


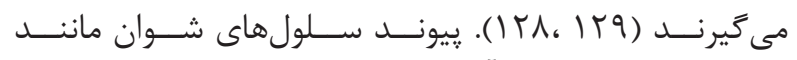

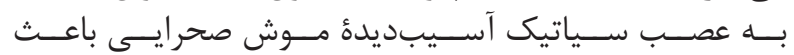

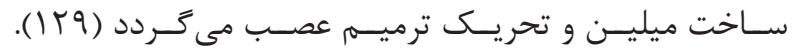

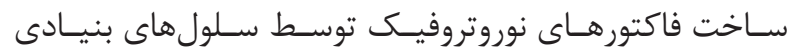

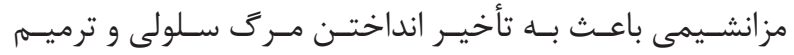

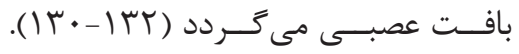

\section{سلولهاى بنيادى يرتوان القايى}

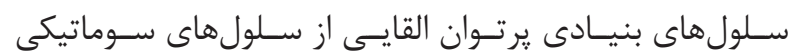

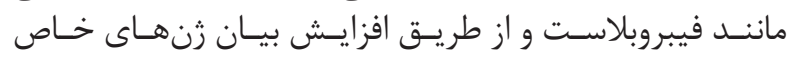
و و ف و Sox2 ،c-Myc ،Oct3/4)

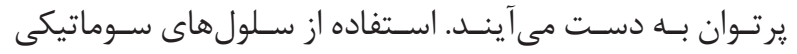

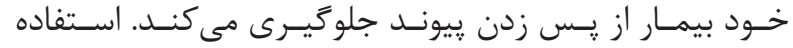

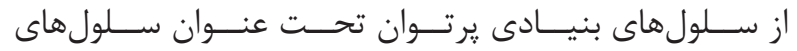

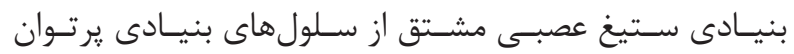

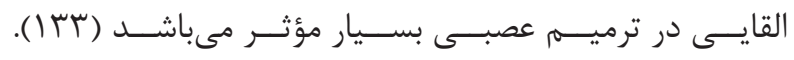

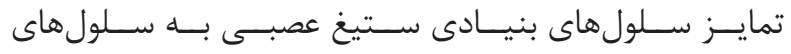

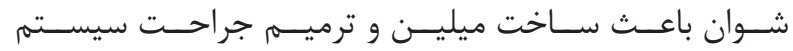

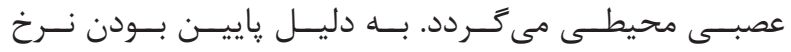

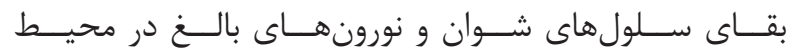

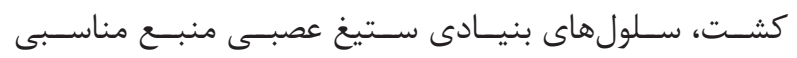

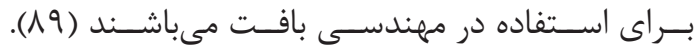

\section{نتيجه كيرى}

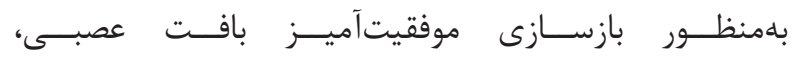

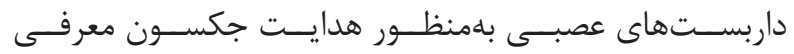

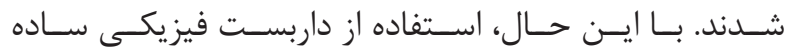

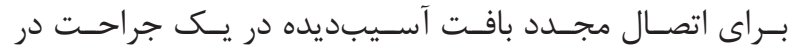

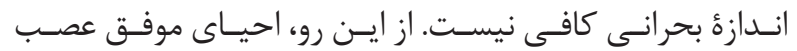

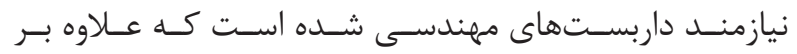

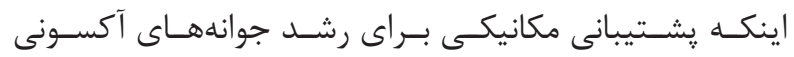

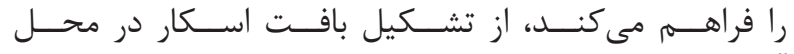

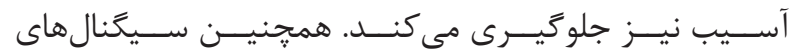

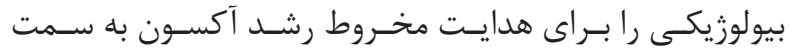

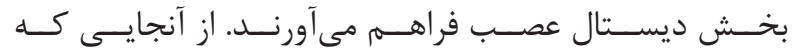

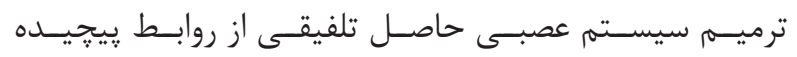

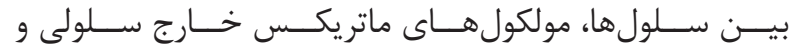

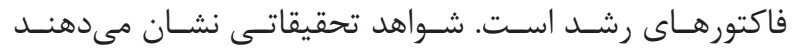

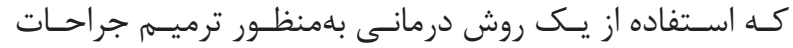

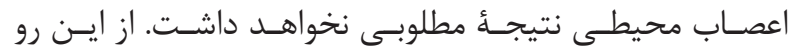

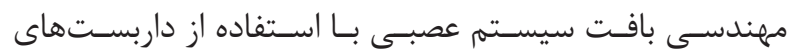

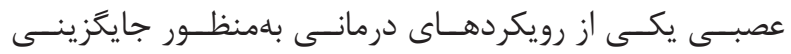

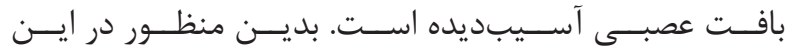

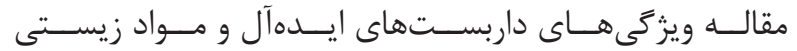

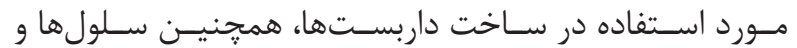

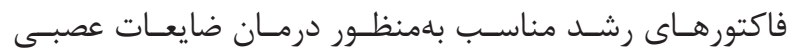

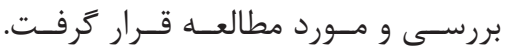

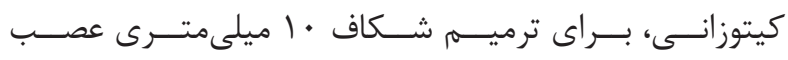

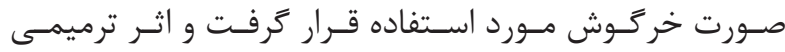

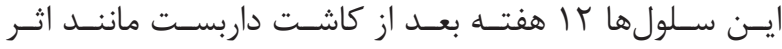

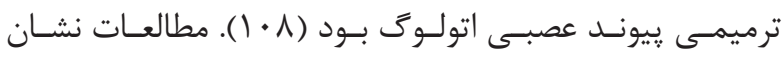

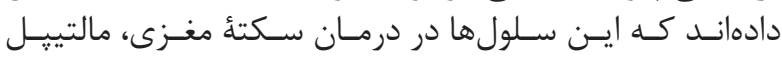

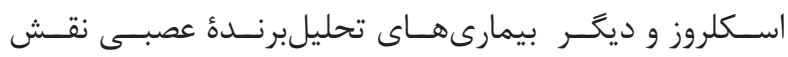

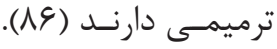

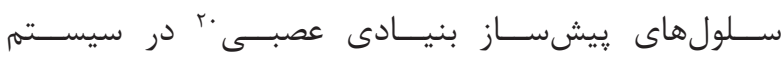

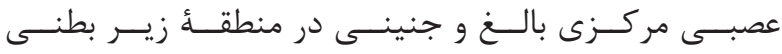

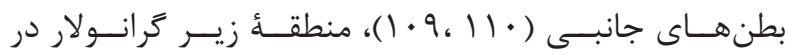

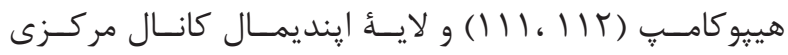

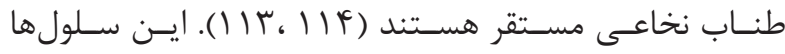

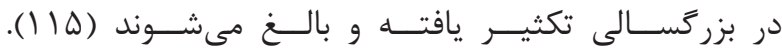

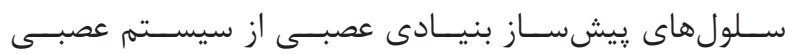

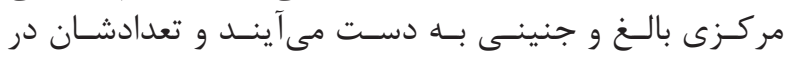

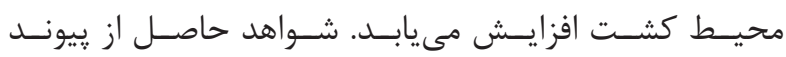

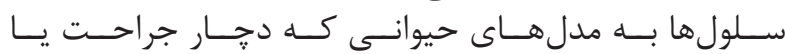

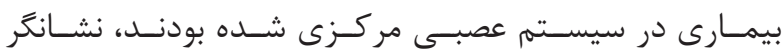

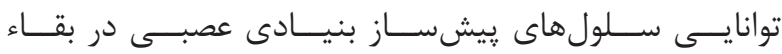

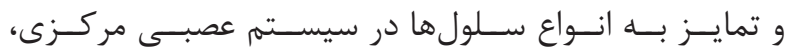

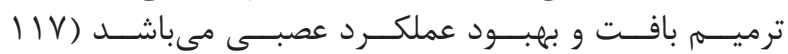

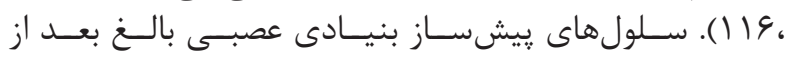

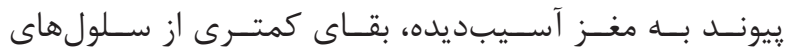

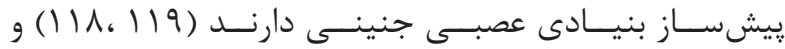

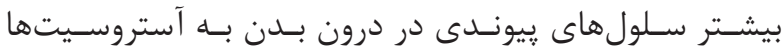

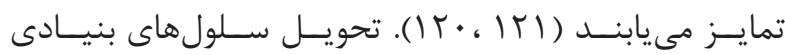

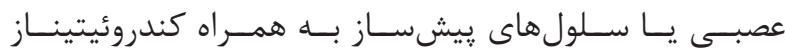

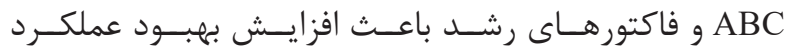

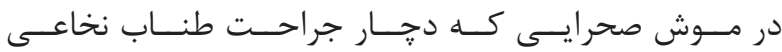

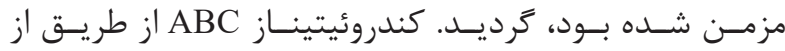

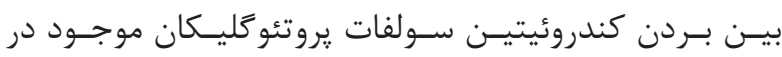

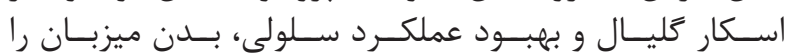

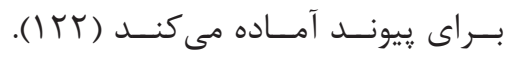
سلول هاى بنيادى مزانشيمى لئى

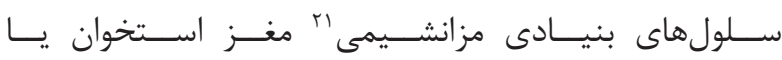

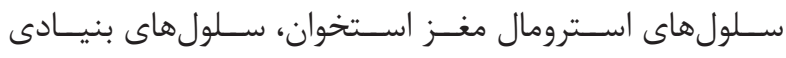

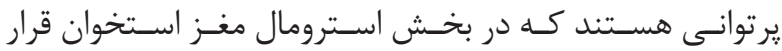

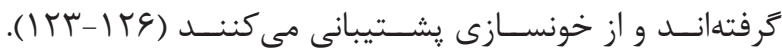

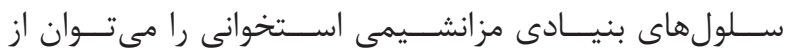

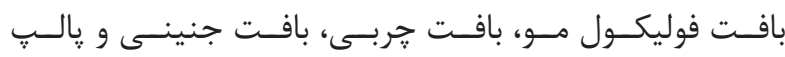

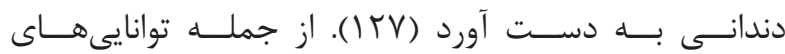

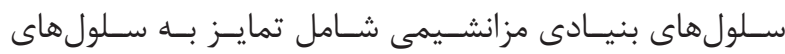

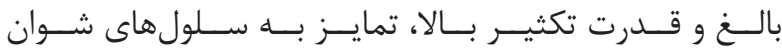

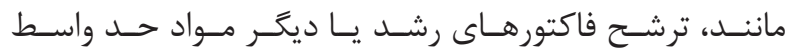

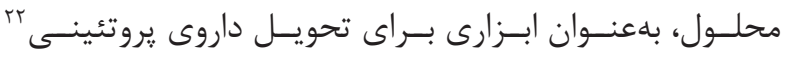

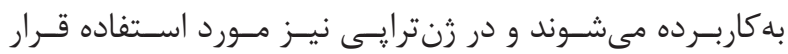


1. Noble J, Munro Ca, Prasad Vs, Midha Rjjot, Surgery Ac. Analysis of upper and lower extremity peripheral nerve injuries in a population of patients with multiple injuries. J Trau Acute Care. 1998; 45(1): 116-22.

2. Artico M, Cervoni L, Nucci F, Giuffre Rjn. Birthday of peripheral nervous system surgery: the contribution of Gabriele Ferrara (1543-1627). Neurosurgery. 1996; 39(2): 380-3.

3. Battiston B, Papalia I, Tos P, Geuna Sjiron. Peripheral nerve repair and regeneration research: a historical note. Int Rev Neurobiol. 2009; 87: 1-7.

4. Lee B, Cripps R, Fitzharris M, Wing PJSc. The global map for traumatic spinal cord injury epidemiology: update 2011, global incidence rate. Spinal Cord. 2014; 52(2): 110-6.

5. Wang Y, Tan H, Hui XJBri. Biomaterial scaffolds in regenerative therapy of the central nervous system. Biomed Res Int. 2018; 2018.

6. Gu X, Ding F, Yang Y, Liu J. Tissue engineering in peripheral nerve regeneration. Neural Regeneration: Elsevier; 2015. p. 73-99.

7. Schmidt CE, Leach JBJArobe. Neural tissue engineering: strategies for repair and regeneration. Annu Rev Biomed Eng. 2003; 5(1): 293-347.

8. Raz A, Perouansky M. Central nervous system physiology: neurophysiology. Pharmacology and Physiology for Anesthesia: Elsevier. 2019; p. 145-73.

9. Trumble TE, Shon FGJHc. The physiology of nerve transplantation. Hand Clin. 2000; 16(1): 105-22.

10. Platt JL, Vercellotti GM, Dalmasso AP, Matas AJ, Bolman RM, Najarian JS, et al. Transplantation of discordant xenografts: a review of progress. Immunol Today. 1990; 11)12): 450-6.

11. Evans PJ, Midha R, Mackinnon SEJPin. The peripheral nerve allograft: a comprehensive review of regeneration and neuroimmunology. Prog Neurobiol. 1994; 43(3): 187-233.

12. Fawcett JW, Asher RAJBrb. The glial scar and central nervous system repair. Brain Res Bull. 1999; 49(6): 377-91.

13. Johnson EO, Soucacos PNJI. Nerve repair: experimental and clinical evaluation of biodegradable artificial nerve guides. Injury. 2008; 39(3): 30-6.

14. Stang F, Keilhoff G, Fansa HJM. Biocompatibility
منابع

of different nerve tubes. Materials. 2009; 2(4): 1480-507.

15. Meek MF, Coert JH. US food and drug administration/ conformit europe-approved absorbable nerve conduits for clinical repair of peripheral and cranial nerves. Ann Plast Surg. 2008; 60(1): 110-6.

16. Deng M, Chen G, Burkley D, Zhou J, Jamiolkowski $\mathrm{D}, \mathrm{Xu} \mathrm{Y}$, et al. A study on in vitro degradation behavior of a poly (glycolide-co-L-lactide) monofilament. Acta Biomater. 2008; 4(5): 1382-91.

17. de Ruiter GC, Malessy MJ, Yaszemski MJDesigning ideal conduits for peripheral nerve repair. Neurosurg Focus. 2009; 26(2): E5.

18. She Z, Zhang B, Jin C, Feng Q, Xu Y. Preparation and in vitro degradation of porous three-dimensional silk fibroin/chitosan scaffold. Polym Degrad Stabil. 2008; 93(7): 1316-22.

19. Zhao Q, Dahlin LB, Kanje M, Lundborg G Repair of the transected rat sciatic nerve: matrix formation within implanted silicone tubes. Restor Neurol Neurosci. 1993; 5(3): 197-204.

20. Abdolmaleki A, Ghayour MB, Zahri S, Asadi A, Behnam-Rassouli M. Preparation of acellular sciatic nerve scaffold and it's mechanical and histological properties for use in peripheral nerve regeneration. Tehran University Medical Journal TUMS Publications. 2019; 77(2): 115-22.

21. Millesi H, Zöch G, Reihsner RJCo, Research R. Mechanical properties of peripheral nerves. Clin Orthop Relat Res. 1995; (314): 76-83.

22. Hollister SJ. Porous scaffold design for tissue engineering. Nat Mater. 2005; 4(7): 518-24.

23. Ahmed Z, Underwood S, Brown RJTE. Nerve guide material made from fibronectin: assessment of in vitro properties. Tissue Eng. 2003; 9(2): 219-31.

24. Zhang Y-G, Huang J-H, Hu X-Y, Sheng Q-S, Zhao W, Luo Z-JJPO. Omentum-wrapped scaffold with longitudinally oriented micro-channels promotes axonal regeneration and motor functional recovery in rats. PLoS One. 2011; 6(12): e29184.

25. Jiang X, Lim SH, Mao H-Q, Chew SYJEn. Current applications and future perspectives of artificial nerve conduits. Exp Neurol. 2010; 223(1): 86-101.

26. Vasita R, Katti DS. Nanofibers and their applications in tissue engineering. Int J Nanomedicine. 2006; 1(1): 15-30. 


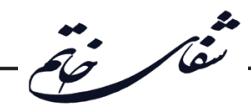

27. Snigdha S ST, Radhakrishnan EK. Polymer based tissue engineering strategies for neural regeneration. Adv Tissue Eng Regen Med Open Access. 2017; 2(1): 1-6.

28. Lee KY, Mooney DJJPips. Alginate: properties and biomedical applications. Prog Polym Sci. 2012; 37(1): 106-26.

29. Shahriari D, Koffler J, Lynam DA, Tuszynski MH, Sakamoto JS. Characterizing the degradation of alginate hydrogel for use in multilumen scaffolds for spinal cord repair. J Biomed Mater Res A. 2016; 104(3): 611-9.

30. Suzuki Y, Kitaura M, Wu S, Kataoka K, Suzuki K, Endo K, et al. Electrophysiological and horseradish peroxidase-tracing studies of nerve regeneration through alginate-filled gap in adult rat spinal cord. Neurosci Lett. 2002; 318(3): 121-4.

31. Marchand R, Woerly S, Bertrand L, Valdes NJBrb. Evaluation of two cross-linked collagen gels implanted in the transected spinal cord. Brain Res Bull. 1993; 30(3-4): 415-22.

32. Barati DP, Roshanaei K, Sahab NS, Aligholi H, Alipour F, Darvishi M. Functional role of natural and synthetic scaffolds in tissue engineering of central nervous system. Shefaye Khatam. 2016; 4(1): 92-77

33. Gámez E, Goto Y, Nagata K, Iwaki T, Sasaki T, Matsuda TJCt. Photofabricated gelatin-based nerve conduits: nerve tissue regeneration potentials. Cell Transplant. 2004; 13(5): 549-64.

34. Avitabile T, Marano F, Castiglione F, Bucolo C, Cro M, Ambrosio L, et al. Biocompatibility and biodegradation of intravitreal hyaluronan implants in rabbits. Biomaterials. 2001; 22(3): 195-200.

35. Özgenel GY.. Effects of hyaluronic acid on peripheral nerve scarring and regeneration in rats. Microsurgery. 2003; 23(6): 575-81.

36. Ghayour MB, Abdolmaleki A, Fereidoni M. Role of extracellular matrix in peripheral nerve regeneration process. RJMS. 2015; 22(135): 75-88.

37. Subramanian A, Krishnan UM, Sethuraman SJJobs. Development of biomaterial scaffold for nerve tissue engineering: Biomaterial mediated neural regeneration. J Biomed Sci. 2009; 16(1): 108. doi: 10.1186/14230127-16-108.

38. Elbert DL, Hubbell JAJB. Conjugate addition reactions combined with free-radical cross-linking for the design of materials for tissue engineering. Biomacromolecules. 2001; 2(2): 430-41.
39. Peppas NA, Keys KB, Torres-Lugo M, Lowman AMJJocr. Poly (ethylene glycol)-containing hydrogels in drug delivery. J Control Release. 1999; 62(1-2): 81-7.

40. Nguyen KT, West JLJB. Photopolymerizable hydrogels for tissue engineering applications. Biomaterials. 2002; 23(22): 4307-14.

41. Burdick JA, Ward M, Liang E, Young MJ, Langer RJB. Stimulation of neurite outgrowth by neurotrophins delivered from degradable hydrogels. Biomaterials. 2006; 27(3): 452-9.

42. Pierluigi T, Alessandro C, Igor P, Luigi V, Davide P, Stefano G, et al. Efficacy of anti-adhesion gel of carboxymethylcellulose with polyethylene oxide on peripheral nerve:experimental results on a mouse mode. Muscle Nerve. 2016; 53(2): 304-9.

43. Athanasiou KA, Niederauer GG, Agrawal CMJB. Sterilization, toxicity, biocompatibility and clinical applications of polylactic acid/polyglycolic acid copolymers. Biomaterials. 1996; 17(2): 93-102.

44. Gunatillake PA, Adhikari RJECM. Biodegradable synthetic polymers for tissue engineering. Eur Cell Mater. 2003; 5(1): 1-16.

45. Nomura H, Tator CH, Shoichet MSJJon. Bioengineered strategies for spinal cord repair. J Neurotrauma. 2006; 23(3-4): 496-507.

46. Zheng Jun Lv, Yang L, Hui M, Zhi QL, Jian Hui $\mathrm{G}$, Jing L. Effects of multiwalled carbon nanotubes on electrospun poly (lactide-co-glycolide)-based nanocomposite scaffolds on neural cells proliferation. J Biomed Mater Res B Appl Biomater. 2016; 105(5): 934-43.

47. Nomura H, Katayama Y, Shoichet MS, Tator CHJN. Complete spinal cord transection treatedby implantation of a reinforced synthetic hydrogel channel results in syringomyelia and caudal migration of the rostral stump. Neurosurgery. 2006; 59(1): 183-92.

48. Tsai EC, Dalton PD, Shoichet MS, Tator CH. Matrix inclusion within synthetic hydrogel guidance channels improves specific supraspinal and local axonal regeneration after complete spinal cord transection. Biomaterials. 2006; 27(3): 519-33.

49. Tsai EC, Dalton PD, Shoichet MS, Tator CH. Synthetic hydrogel guidance channels facilitate regeneration of adult rat brainstem motor axons after complete spinal cord transection. J Neurotrauma. 2004; 21(6): 789-804.

50. Carone TW, Hasenwinkel JM, The Japanese society 
for biomaterials, biomaterials TASf, biomaterials tKSf. mechanical and morphological characterization of homogeneous and bilayered poly (2-hydroxyethyl methacrylate) scaffolds for use in CNS nerve regeneration. J Biomed Mater Res B Appl Biomater. 2006; 78(2): 274-82.

51. Hajj Hassan M, Chodavarapu V, Musallam SJS. NeuroMEMS: neural probe microtechnologies. Sensors. 2008; 8(10): 6704-26.

52. Ghasemi-Mobarakeh L, Prabhakaran MP, Morshed M, Nasr-Esfahani MH, Baharvand H, Kiani S, et al. Application of conductive polymers, scaffolds and electrical stimulation for nerve tissue engineering. J Tissue Eng Regen Med. 2011; 5(4): e17-e35.

53. Terenghi G. Peripheral nerve regeneration and neurotrophic factors. J Anat. 1999; 194(1): 1-14.

54. Pfister LA, Papaloïzos M, Merkle HP, Gander B. Nerve conduits and growth factor delivery in peripheral nerve repair. J Peripher Nerv Syst. 2007; 12(2): 65-82.

55. Tayalia P, Mooney DJ. Controlled growth factor delivery for tissue engineering. Adv Mater. 2009; 21(32-33): $\quad 3269-85$.

56. Chalfoun C, Wirth G, Evans G. Tissue engineered nerve constructs: where do we stand? J Cell Mol Med. 2006; 10(2): 309-17.

57. Taylor SJ, Rosenzweig ES, McDonald III JW, Sakiyama-Elbert SE. Delivery of neurotrophin-3 from fibrin enhances neuronal fiber sprouting after spinal cord injury. J Control Release. 2006; 113(3): 226-35.

58. Khaksar Z, Morovvati H, Moradi HR, Negah SS. The role of extracellular matrix in myelination and oligodendrogenesis of the central nervous system. Shefaye Khatam. 2019; 7(2):66-82

59. Yin Q, Kemp GJ, Yu LG, Wagstaff SC, Frostick SP. Neurotrophin-4 delivered by fibrin glue promotes peripheral nerve regeneration. Muscle Nerve. 2001; 24(3): 345-51.

60. Siegel GJ. Basic neurochemistry: molecular, cellular and medical aspects. $6^{\text {th }}$ ed. Philadelphia: LippincottRaven; 1999.

61. Fine EG, Decosterd I, Papaloïzos M, Zurn AD, Aebischer P. GDNF and NGF released by synthetic guidance channels support sciatic nerve regeneration across a long gap. Eur J Neurosci. 2002; 15(4): 589-601.

62. Sahenk Z, Seharaseyon J, Mendell JR. CNTF potentiates peripheral nerve regeneration. Brain Res. 1994; 655(1-2): 246-50.
63. Rich KM, Alexander TD, Pryor JC, Hollowell JP. Nerve growth factor enhances regeneration through silicone chambers. Exp Neurol. 1989; 105(2): 162-70.

64. Bu SS, Li JR, Hu CZ, Zhao YF. The influence of exogenous nerve growth factor on inferior alveolar nerve regeneration in silicone tubes. Chin J Dent Res. 1999; 2(3-4): 44-8.

65. Boyd J, Gordon T. A dose-dependent facilitation and inhibition of peripheral nerve regeneration by brainderived neurotrophic factor. Eur J Neurosci. 2002; 15(4): 613-26.

66. Boyd J, Gordon T. Glial cell line-derived neurotrophic factor and brain-derived neurotrophic factor sustain the axonal regeneration of chronically axotomized motoneurons in vivo. Exp Neuro. 2003; 183(2): 610-9.

67. Santos X, Rodrigo J, Hontanilla B, Bilbao G. Evaluation of peripheral nerve regeneration by nerve growth factor locally administered with a novel system. J Neurosci Methods. 1998; 85(1): 119-27.

68. Santos X, Rodrigo J, Hontanilla B, Bilbao G. Local administration of neurotrophic growth factor in subcutaneous silicon chambers enhances the regeneration of the sensory component of the rat sciatic nerve. Microsurgery. 1999; 19(6): 275-80.

69. Whitworth I, Brown R, Dore C, Anand P, Green C, Terenghi G. Nerve growth factor enhances nerve regeneration through fibronectin grafts. J Hand Surg. 1996; 21(4): 514-22.

70. Yang Y, Zhao W, He J, Zhao Y, Ding F, Gu X. Nerve conduits based on immobilization of nerve growth factor onto modified chitosan by using genipin as a crosslinking agent. Eur J Pharm Biopharm. 2011; 79(3): 519-25.

71. Benoit J-P, Faisant N, Venier-Julienne M-C, Menei P. Development of microspheres for neurological disorders: from basics to clinical applications. J Control Release. 2000; 65(1-2): 285-96.

72. Xu X, Yu H, Gao S, Mao H-Q, Leong KW, Wang $\mathrm{S}$. Polyphosphoester microspheres for sustained release of biologically active nerve growth factor. Biomaterials. 2002; 23(17): 3765-72.

73. Xu X, Yee W-C, Hwang PY, Yu H, Wan AC, Gao S, et al. Peripheral nerve regeneration with sustained release of poly (phosphoester) microencapsulated nerve growth factor within nerve guide conduits. Biomaterials. 2003; 24(13): 2405-12.

74. Tan SA, Aebischer P. The problems of delivering neuroactive molecules to the CNS. Gregory R. Bock, Jamie A. Growth factors as drugs for neurological and 


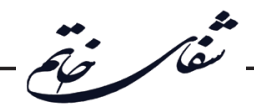

sensory disorders. 1996;p. 211-36.

75. Haller MF, Saltzman WM. Nerve growth factor delivery systems. J Control Release. 1998; 53: 1-6.

76. Starr PA, Wichmann T, van Horne C, Bakay RA. Intranigral transplantation of fetal substantia nigra allograft in the hemiparkinsonian rhesus monkey. Cell Transplant. 1999; 8(1): 37-45.

77. Sautter J, Tseng J, Braguglia D, Aebischer P, Spenger C, Seiler R, et al. Implants of polymer-encapsulated genetically modified cells releasing glial cell linederived neurotrophic factor improve survival, growth, and function of fetal dopaminergic grafts. Exp Neurol. 1998; 149(1): 230-6.

78. Tuszynski MH, Weidner N, McCormack M, Miller I, Powell H, Conner J. Grafts of genetically modified Schwann cells to the spinal cord: survival, axon growth, and myelination. Cell Transplant. 1998; 7(2): 187-96.

79. Emerich DF, Hammang JP, Baetge EE, Winn SR. Implantation of polymer-encapsulated human nerve growth factor-secreting fibroblasts attenuates the behavioral and neuropathological consequences of quinolinic acid injections into rodent striatum. Exp Neurol. 1994; 130(1): 141-50.

80. Kordower JH, Winn SR, Liu Y-T, Mufson EJ, Sladek JR, Hammang JP, et al. The aged monkey basal forebrain: rescue and sprouting of axotomized basal forebrain neurons after grafts of encapsulated cells secreting human nerve growth factor. Proc Natl Acad Sci. 1994; 91(23): 10898-902.

81. Lindner MD, Winn SR, Baetge E, Hammang JP, Gentile FT, Doherty E, et al. Implantation of encapsulated catecholamine and GDNF-producing cells in rats with unilateral dopamine depletions and parkinsonian symptoms. Exp Neuro. 1995; 132(1):62-76

82. Aebischer P, Schluep M, Déglon N, Joseph J-M, Hirt L, Heyd B, et al. Intrathecal delivery of CNTF using encapsulated genetically modifiedxenogeneic cells in amyotrophic lateral sclerosis patients. Nat Med. 1996; 2(6): 696-9.

83. Winn SR, Hammang JP, Emerich DF, Lee A, Palmiter RD, Baetge EE. Polymer-encapsulated cells genetically modified to secrete human nerve growth factor promote the survival of axotomized septal cholinergic neurons. Proc Natl Acad Sci. 1994; 91(6): 2324-8.

84. Xu XM, Guénard V, Kleitman N, Aebischer P, Bunge MB. A combination of BDNF and NT-3 promotes supraspinal axonal regeneration into Schwann cell grafts in adult rat thoracic spinal cord. Exp Neuro. 1995; 134(2): 261-72.
85. Babensee JE, McIntire LV, Mikos AG. Growth factor delivery for tissue engineering. Pharm Res. 2000; 17(5): 497-504.

86. Sensharma P, Madhumathi G, Jayant RD, Jaiswal AK. Biomaterials and cells for neural tissue engineering: current choices. Mater Sci Eng C. 2017; 77: 1302-15.

87. Shoichet Slpbgbmdmjcm S. Principles of regenerative medicine. $3^{\text {th }}$ ed. 2019; p. 1199-221.

88. Jesuraj NJ, Santosa KB, Macewan MR, Moore AM, Kasukurthi R, Ray WZ, et al. Schwann cells seeded in acellular nerve grafts improve functional recovery. Muscle Nerve. 2014; 49(2): 267-76.

89. Ghayour MB, Abdolmaleki A, Fereidoni M. Use of stem cells in the regeneration of peripheral nerve injuries: an overview. Shefaye Khatam. 2015; 3(1): 8498.

90. Khataokar A, Skop N, Kim H, Pfister B, Cho CH. Development of schwann cell-seeded conduit using chitosan-based biopolymers for nerve repair. 36th Annual Northeast Bioengineering Conference (NEBEC). 2010.

91. Guenard V, Kleitman N, Morrissey T, Bunge R, Aebischer P. Syngeneic schwann cells derived from adult nerves seeded in semipermeable guidance channels enhance peripheral nerve regeneration. J Neurosci. 1992; 12(9): 3310-20.

92. Rodríguez FJ, Verdú E, Ceballos D, Navarro X. Nerve guides seeded with autologous Schwann cells improve nerve regeneration. Exp Neurol. 2000; 161(2): 571-84.

93. Mosahebi A, Woodward B, Wiberg M, Martin R, Terenghi G. Retroviral labeling of Schwann cells: in vitro characterization and in vivo transplantation to improve peripheral nerve regeneration. Glia. 2001; 34(1): 8-17.

94. Li X, Gonias SL, Campana WM. Schwann cells express erythropoietin receptor and represent a major target for Epo in peripheral nerve injury. Glia. 2005; 51(4): 254-65.

95. Ding F, Wu J, Yang Y, Hu W, Zhu Q, Tang X, et al. Use of tissue-engineered nerve grafts consisting of a chitosan/poly (lactic-co-glycolic acid)-based scaffold included with bone marrow mesenchymal cells for bridging 50-mm dog sciatic nerve gaps. Tissue Eng Part A. $2010 ; 16(12): 3779-90$.

96. Yang Y, Yuan X, Ding F, Yao D, Gu Y, Liu J, et al. Repair of rat sciatic nerve gap by a silk fibroin-based scaffold added with bone marrow mesenchymal stem cells. Tissue Eng Part A. 2011; 17(17-18): 2231-44.

97. Xue C, Hu N, Gu Y, Yang Y, Liu Y, Liu J, et al. Joint 
use of a chitosan/PLGA scaffold and MSCs to bridge an extra large gap in dog sciatic nerve. Neurorehabil Neural Repair. 2012; 26(1): 96-106.

98. Hu N, Wu H, Xue C, Gong Y, Wu J, Xiao Z, et al. Long-term outcome of the repair of $50 \mathrm{~mm}$ long median nerve defects in rhesus monkeys with marrow mesenchymal stem cells-containing, chitosan-based tissue engineered nerve grafts. Biomaterials. 2013; 34(1): 100-11.

99. Jakob H. Stem cells and embryo-derived cell lines: tools for study of gene expression. Cell Differentiation. 1984; 15(2-4): 77-80.

100. Rodrigues MCO, Rodrigues AA, Glover LE, Voltarelli J, Borlongan CV. Peripheral nerve repair with cultured schwann cells: getting closer to the clinics. Sci World J. 2012; 2012. doi: 10.1100/2012/413091

101. Cui L, Jiang J, Wei L, Zhou X, Fraser JL, Snider BJ, et al. Transplantation of embryonic stem cells improves nerve repair and functional recovery after severe sciatic nerve axotomy in rats. Stem Cells. 2008; 26(5): 135665 .

102. Yohn DC, Miles GB, Rafuse VF, Brownstone RM. Transplanted mouse embryonic stem-cell-derived motoneurons form functional motor units and reduce muscle atrophy. J Neurosci. 2008; 28(47): 12409-18.

103. Craff MN, Zeballos JL, Johnson TS, Ranka MP, Howard R, Motarjem P, et al. Embryonic stem cellderived motor neurons preserve muscle after peripheral nerve injury. Plast Reconstr Surg. 2007; 119(1): 235-45.

104. Gökhan Ş, Mehler MF. Basic and clinical neuroscience applications of embryonic stem cells. Anat Rec. 2001; 265(3): 142-56.

105. Alessandri G, Emanueli C, Madeddu P. Genetically engineered stem cell therapy for tissue regeneration. Ann N Y Acad Sci. 2004; 1015(1): 271-84.

106. Heine W, Conant K, Griffin JW, Höke A. Transplanted neural stem cells promote axonal regeneration through chronically denervated peripheral nerves. Exp Neuro. 2004; 189(2): 231-40.

107. Xiong Y, Zeng Y-S, Zeng C-G, Du B-1, He L-M, Quan D-P, et al. Synaptic transmission of neural stem cells seeded in 3-dimensional PLGA scaffolds. Biomaterials. 2009; 30(22): 3711-22.

108. Guo B-F, Dong M-M. Application of neural stem cells in tissue-engineered artificial nerve. Otolaryngol. Head Neck Surg. 2009; 140(2): 159-64.
109. Chiasson BJ, Tropepe V, Morshead CM, Van Der Kooy D. Adult mammalian forebrain ependymal and subependymal cells demonstrate proliferative potential, but only subependymal cells have neural stem cell characteristics. J Neurosci. 1999; 19(11): 4462-71.

110. Morshead CM, Reynolds BA, Craig CG, McBurney MW, Staines WA, Morassutti D, et al. Neural stem cells in the adult mammalian forebrain: a relatively quiescent subpopulation of subependymal cells. Neuron. 1994; 13(5): 1071-82.

111. Kuhn HG, Dickinson-Anson H, Gage FH. Neurogenesis in the dentate gyrus of the adult rat: agerelated decrease of neuronal progenitor proliferation. $\mathrm{J}$ Neurosci. 1996; 16(6): 2027-33.

112. Palmer TD, Takahashi J, Gage FH. The adult rat hippocampus contains primordial neural stem cells. Mol Cell Neurosci. 1997; 8(6): 389-404.

113. Horner PJ, Power AE, Kempermann G, Kuhn HG, Palmer TD, Winkler J, et al. Proliferation and differentiation of progenitor cells throughout the intact adult rat spinal cord. J Neurosci. 2000; 20(6): 2218-28.

114. Weiss S, Dunne C, Hewson J, Wohl C, Wheatley M, Peterson AC, et al. Multipotent CNS stem cells are present in the adult mammalian spinal cord and ventricular neuroaxis. J Neurosci. 1996; 16(23): 7599609.

115. Bambakidis NC, Wang R-Z, Franic L, Miller RH. Sonic hedgehog-induced neural precursor proliferation after adult rodent spinal cord injury. J Neurosurg Spine. 2003; 99(1): 70-5.

116. Ben-Hur T, Einstein O, Mizrachi-Kol R, Ben-Menachem O, Reinhartz E, Karussis D, et al. Transplanted multipotential neural precursor cells migrate into the inflamed white matter in response to experimental autoimmune encephalomyelitis. Glia. 2003; 41(1): 73-80.

117. Ishibashi S, Sakaguchi M, Kuroiwa T, Yamasaki M, Kanemura Y, Shizuko I, et al. Human neural stem/ progenitor cells, expanded in long-term neurosphere culture, promote functional recovery after focal ischemia in mongolian gerbils. J Neurosci Res. 2004; 78(2): 215-23.

118. Fricker-Gates RA, Shin JJ, Tai CC, Catapano LA, Macklis JD. Late-stage immature neocortical neurons reconstruct interhemispheric connections and form synaptic contacts with increased efficiency in adult mouse cortex undergoing targeted neurodegeneration. J Neurosci. 2002; 22(10): 4045-56. 


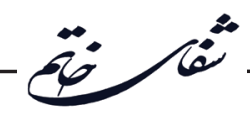

119. Nakagomi N, Nakagomi T, Kubo S, Nakano-Doi A, Saino O, Takata M, et al. Endothelial cells support survival, proliferation, and neuronal differentiation of transplanted adult ischemia-induced neural stem/ progenitor cells after cerebral infarction. Stem Cells. 2009; 27(9): 2185-95.

120. Dziewczapolski G, Lie D, Ray J, Gage F, Shults C. Survival and differentiation of adult rat-derived neural progenitor cells transplanted to the striatum of hemiparkinsonian rats. Exp Neurol. 2003; 183(2): 653-64.

121. Herrera DG, Garcia-Verdugo JM, Alvarez-Buylla A. Adult-derived neural precursors transplanted into multiple regions in the adult brain. Ann Neurol. 1999; 46(6): 867-77.

122. Karimi-Abdolrezaee S, Eftekharpour E, Wang J, Schut D, Fehlings MG. Synergistic effects of transplanted adult neural stem/progenitor cells, chondroitinase, and growth factors promote functional repair and plasticity of the chronically injured spinal cord. J Neurosci. 2010; 30(5):1657-76.

123. Abdallah B, Kassem M. Human mesenchymal stem cells: from basic biology to clinical applications. Gene Ther. 2008; 15(2): 109-16.

124. Phinney DG, Prockop DJ. Concise review: mesenchymal stem/multipotent stromal cells: the state of transdifferentiation and modes of tissue repair-current views. Stem Cells. 2007; 25(11): 2896-902.

125. Bianco P, Riminucci M, Gronthos S, Robey PG. Bone marrow stromal stem cells: nature, biology, and potential applications. Stem Cells. 2001; 19(3): 180-
92.

126. Deryugina E, Müller-Sieburg C. Stromal cells in long-term cultures: keys to the elucidation of hematopoietic development? Crit Rev Immunol. 1993; 13(2): 115-50.

127. Brun P, Cortivo R, Zavan B, Vecchiato N, Abatangelo $\mathrm{G}$. In vitro reconstructed tissues on hyaluronan-based temporary scaffolding. J Mater Sci: Mater Med. 1999; 10(10-11): 683-8.

128. Horwitz E, Dominici M. How do mesenchymal stromal cells exert their therapeutic benefit? Cytotherapy. 2008; 10(8): 771-4.

129. Keilhoff G, Fansa H. Mesenchymal stem cells for peripheral nerve regeneration-a real hope or just an empty promise? Exp Neurol. 2011; 232(2): 110-3.

130. Chopp M, Li Y. Treatment of neural injury with marrow stromal cells. Lancet Neurol. 2002; 1(2): 92-100.

131. Chopp M, Zhang XH, Li Y, Wang L, Chen J, Lu $\mathrm{D}$, et al. Spinal cord injury in rat: treatment with bone marrow stromal cell transplantation. Neuroreport. 2000; 11(13): 3001-5.

132. Gu Y, Wang J, Ding F, Hu N, Wang Y, Gu X Neurotrophic actions of bone marrow stromal cells on primary culture of dorsal root ganglion tissues and neurons. J Mol Neurosci. 2010; 40(3): 332-41.

133. Lee Y-S, Livingston Arinzeh T. Electrospun nanofibrous materials for neural tissue engineering. Polymers. 2011; 3(1): 413-26. 